\section{G员员乨 REPORT 87-21}

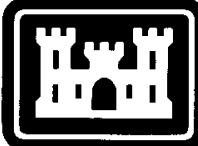

US Army Corps of Engineers

Cold Regions Research \& Engineering Laboratory

\title{
Spectral measurements in a disturbed boundary layer over snow
}

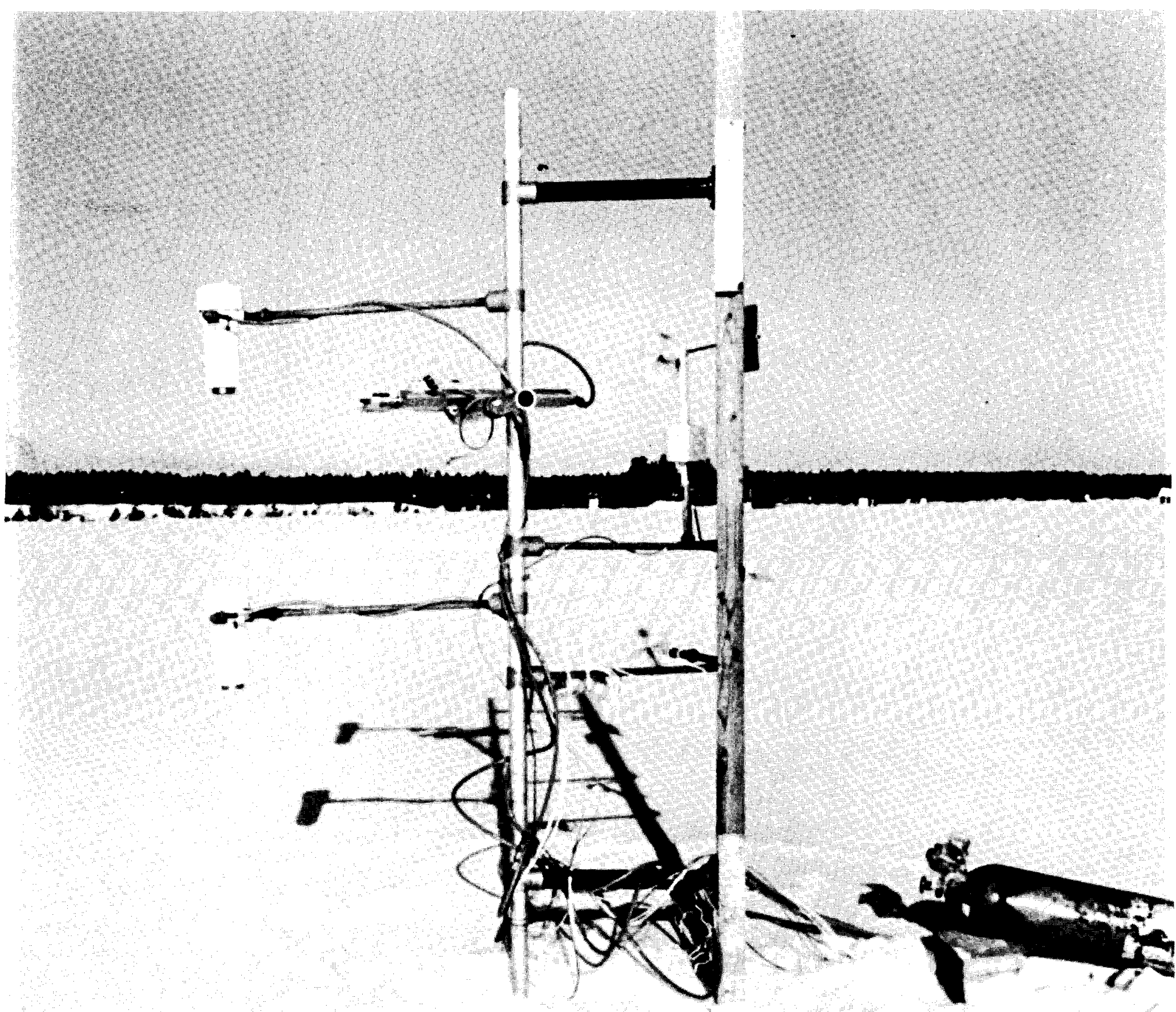




\section{CRREL Report 87-21}

November 1987

\section{Spectral measurements in a disturbed boundary layer over snow}

Edgar L Andreas 
REPORT DOCUMENTATION PAGE

1a. REPORT SECURITY CLASSIFICATION

1b. RESTRICTIVE MARKINGS

Unclassified

2a SECURITY CLASSIFICATION AUTHORITY

3. DISTRIBUTION/AVAILABILITY OF REPORT

2b. DECLASSIFICATION/DOWNGRADING SCHEDULE

Approved for public release;

distribution is unlimited.

4. PERFORMING ORGANIZATION REPORT NUMBER(S)

5. MONITORING ORGANIZATION REPORT NUMBER(S)

CRREL Report 87-21

6a. NAME OF PERFORMING ORGANIZATION

U.S. Ármy Cold Regions Research

and Engineering Laboratory

6c. ADDRESS (City, State, and ZIP Code)

Hanover, New Hampshire 03755-1290

6b. OFFICE SYMBOL

(If applicable)

CECRL

7a. NAME OF MONITORING ORGANIZATION

Office of the Chief of Engineers

7b. ADDRESS (City, State, and ZIP Code)

Washington, D.C. 20314-1000

8a. NAME OF FUNDING/SPONSORING ORGANIZATION

8b. OFFICE SYMBOL

9. PROCUREMENT INSTRUMENT IDENTIFICATION NUMBER

(If applicable)

8c. ADDRESS (City, State, and ZIP Code)

10. SOURCE OF FUNDING NUMBERS

\begin{tabular}{l|l|l|l}
\hline $\begin{array}{l}\text { PROGRAM } \\
\text { ELEMENT NO. }\end{array}$ & $\begin{array}{l}\text { PROJECT } \\
\text { NO. } 4 \text { A } 1611 \\
02 A T 24\end{array}$ & $\begin{array}{l}\text { TASK } \\
\text { NO. }\end{array}$ & $\begin{array}{l}\text { WORK UNIT } \\
\text { ACCESSION NO } \\
002\end{array}$ \\
\hline
\end{tabular}

11. TITLE (Include Security Classification)

Spectral Measurements in a Disturbed Boundary Layer Over Snow

12. PERSONAL AUTHOR(S)

Andreas, Edgar L

13a. TYPE OF REPORT

13b. TIME COVERED

FROM

TO

14. DATE OF REPORT (Year, Month, Day) Novem ber 1987

15. PAGE COUNT

50

16. SUPPLEMENTARY NOTATION

17

COSATI CODES

\begin{tabular}{l|l|l}
\hline FIELD & GROUP & SUB-GROUP \\
\hline
\end{tabular}

8. SUBJECT TERMS (Continue on reverse if necessary and identify by block number)

Atmosphere

Boundary layer

Turbulence

19. ABSTRACT (Continue on reverse if necessary and identify by block number)

The author measured time series of longitudinal $(u)$ and vertical $(w)$ veiocity and temperature $(t)$ and humidity $(q)$ fluctuations with fast-responding sensors in the near-neutrally stable surface layer over a snow-covered field. These series yielded individual spectra and $u-w, w-q$ and $t-q$ cospectra, phase spectra and coherence spectra for nondimensional frequencies $(f z, U)$ from roughly 0.001 to 10 . This is, thus, one of the most extensive spectral sets ever collected over a snow-covered surface. With the exception of the $u-w$ cospectra, all of the spectra and cospectra displayed the expected dependence on frequency in an inertial or inertial-convective subrange. All, however, contained significantly more energy at low frequency than the Kansas neutral-stability spectra and cospectra. This excess low-frequency energy and the erratic behavior of the $u-w$ cospectra imply that the forested hills bordering the site on two sides were producing disturbances in the flow field at scales roughly equal to the height of the hills, $100 \mathrm{~m}$. The phase and coherence spectra suggest that internal gravity waves were also frequently present, since the atmospheric boundary layer generally had slightly stable stratification. Consequently, at this complex site, turbulence alone determines the spectra and cospectra at high frequency; at low frequency

20. DISTRIBUTION / AVAILABILITY OF ABSTRACT

$₫$ UNCLASSIFIED/UNLIMITED $\square$ SAME AS RPT.

22a. NAME OF RESPONSIBLE INDIVIDUAL

Edgar L Andreas

\begin{tabular}{|c|c|}
\hline$\square$ DTIC USERS & $\begin{array}{l}\text { 21. ABSTRACT SECURITY CLASSIFICA } \\
\text { Unclassified }\end{array}$ \\
\hline & $\begin{array}{l}\text { 22b. TELEPHONE (Include Area Code) } \\
603-646-4100\end{array}$ \\
\hline
\end{tabular}

603-646-4100

CECRL-RS 


\section{Unclassified}

\section{Abstract (cont'd)}

the spectra and cospectra reflect a combination of topographically generated turbulence and internal waves. From the measured temperature and humidity spectra and the $t-q$ cospectra, the author computed refractive index spectra for light of $0.55-\mu \mathrm{m}$ and millimeter wavelengths, the first such spectra obtained over snow. The ref ractive index spectra had shapes like the other scalar spectra: excess energy at low frequency and an inertial-convective subrange at high frequency. The existence of an inertial-convective subrange allowed computation of the refractive index structure parameter $C_{n}^{2}$ for each spectrum. Values of $C_{n}^{2}$ ranged from $9 \times 10^{-17}$ to $6 \times 10^{-15} \mathrm{~m}^{-2 / 3}$ for visible wavelengths and from $8 \times 10^{-16}$ to $1.5 \times 10^{-14} \mathrm{~m}^{-2 / 3}$ for millimeter wavelengths. From the $u, t$ and $q$ spectra, the author also estimated the surface sensible $\left(H_{\mathrm{S}}\right)$ and latent $\left(H_{\mathrm{L}}\right.$ ) heat fluxes using the inertial-dissipation technique. The absolute value of $H_{\mathrm{S}}$ rarely exceeded $10 \mathrm{~W} \mathrm{~m}^{-2}$; the absolute value of $H_{\mathrm{L}}$ was always less than 10 $\mathrm{W} \mathrm{m} \mathrm{m}^{-2}$. Though $H_{\mathrm{s}}$ could take on either sign, $H_{\mathrm{L}}$ was virtually always positive-the snow was subliming. 


\section{PREFACE}

This report was prepared by Dr. Edgar L Andreas, Physicist, Snow and Ice Branch, Research Division, U.S. Army Cold Regions Research and Engineering Laboratory. The Office of the Chief of Engineers supported this research with DA Project 4A161102AT24, Research in Snow, Ice and Frozen Ground; Task FS, Fire Support; Work Unit 002, Winter Surface Boundary Layer Physics.

The author thanks Robert Redfield for field support; Brett Murphy for helping with the data analysis and the plotting; William Bates for doing the drafting; Robert Olsen of the Atmospheric Sciences Laboratory, White Sands, New Mexico, and Roy Bates of CRREL for supplying the scintillometer data; Austin Hogan and Don Perovich for helpful reviews of the manuscript; and Mark Hardenberg and David Cate for editorial assistance.

The contents of this report are not to be used for advertising or promotional purposes. $\mathrm{Ci}$ tation of brand names does not constitute an official endorsement or approval of the use of such commercial products. 


\section{CONTENTS}

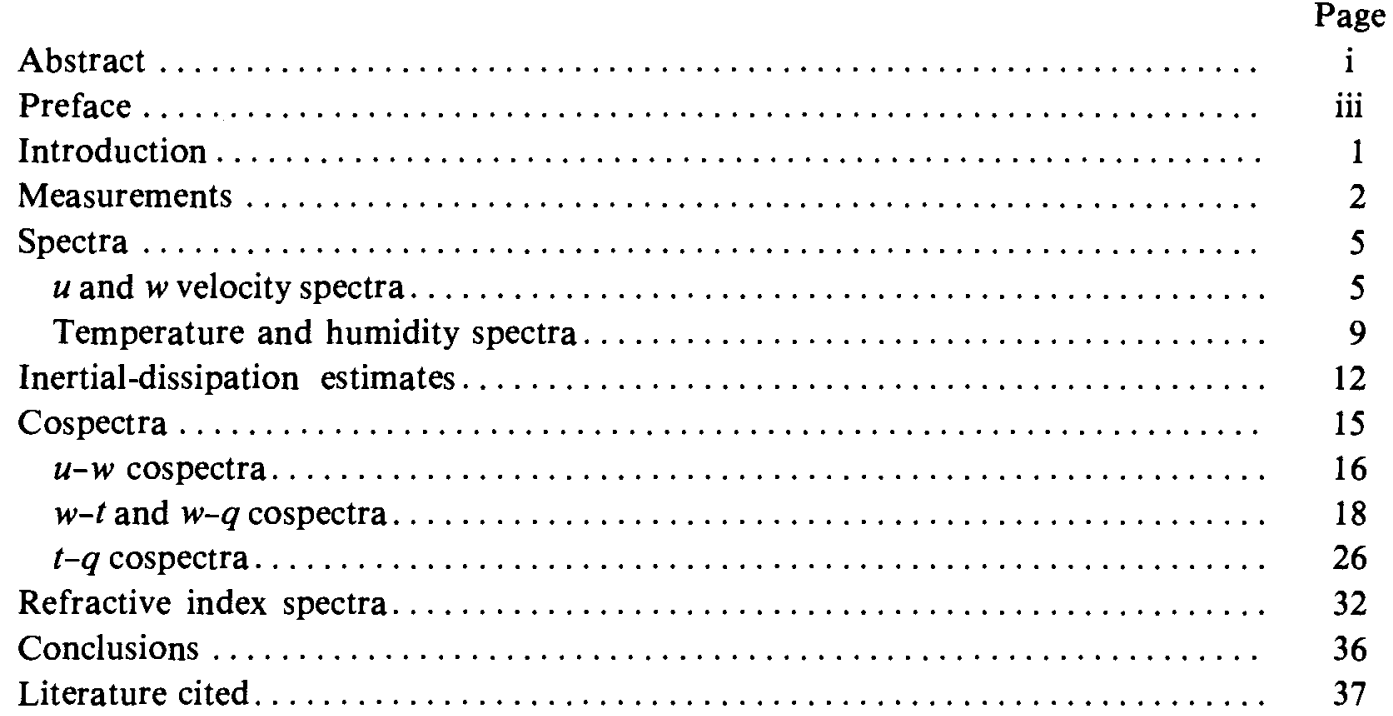

\section{ILLUSTRATIONS}

Figure

1. Topography of the experimental site...................... 3

2. The instrument mast, with two levels for measuring the average quantities $U, T$ and $Q$, and a 2-m measurement of the turbulent fluctuations $u, w, t$ and $q . \quad 4$

3. Nondimensional $u$ velocity spectrum for each run in Table $1 \ldots \ldots \ldots \ldots \ldots$. 7

4. Twenty-two nondimensional $w$ velocity spectra ................. 7

5. Twenty-four nondimensional temperature spectra ............... 10

6. Twenty-four nondimensional humidity spectra ................. 10

7. Plots of the $u-w$ cospectrum, phase spectrum and coherence spectrum for each

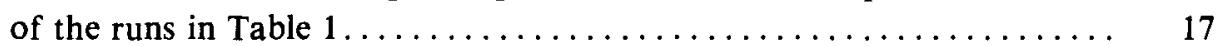

8. Plots of $u-w$ cospectra, phase spectra and coherence spectra for the runs in Table 1 in which $C o_{u w}$ was negative in the inertial subrange $\ldots \ldots \ldots \ldots \quad 19$

9. Plots of $w-t$ cospectra, phase spectra and coherence spectra for 16 runs in which $\mathrm{Co}_{\mathrm{wt}}$ was predominantly negative in the inertial-convective subrange....

10. Plots of $w-t$ cospectra, phase spectra and coherence spectra for five runs in which $\mathrm{Co}_{\mathrm{wt}}$ was positive in the inertial-convective subrange.........

11. Plots of $w-q$ cospectra, phase spectra and coherence spectra for 22 runs in which $\mathrm{Co}_{\text {wq }}$ was positive in the inertial-convective subrange........

12. Plots of the $w-q$ cospectrum, phase spectrum and coherence spectrum for the one run in which $\mathrm{Co}_{\mathrm{wq}}$ was negative in the inertial-convective subrange...

13. Plots of $t-q$ cospectra, phase spectra and coherence spectra for 12 runs in which $\mathrm{Co}_{\mathrm{tq}}$ was predominantly negative in the inertial-convective subrange....

14. Plots of $t-q$ cospectra, phase spectra and coherence spectra for five runs in which $\mathrm{Co}_{\mathrm{tq}}$ was positive in the inertial-convective subrange $\ldots \ldots \ldots \ldots$

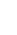

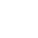
7 (7)

0


15. Twenty-four nondimensional refractive index spectra for light of $0.55-\mu \mathrm{m}$

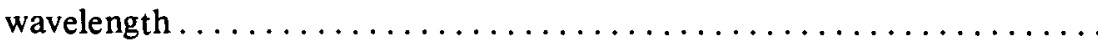

16. Twenty nondimensional refractive index spectra for light of near-millimeter

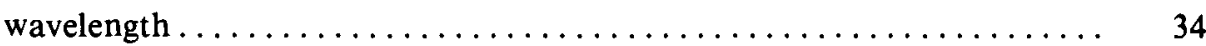

17. Comparison of simultaneous scintillometer and spectrally derived values of $C_{n}^{2}$

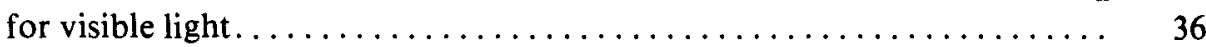

\section{TABLES}

\section{Table}

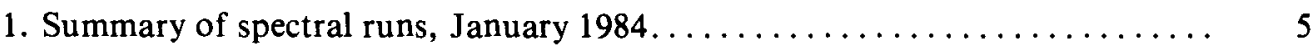

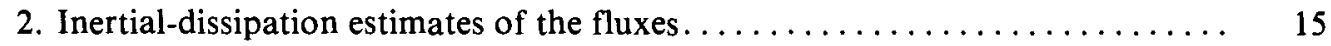

3. Functions $A$ and $B$ for $0.55-\mu \mathrm{m}$ and millimeter wavelengths........... 32

4. Values of the spectrally derived refractive index structure parameters for 0.55 $\mu \mathrm{m}$ and millimeter wavelengths and the relative contributions of temperature and humidity fluctuations and the $t-q$ covariance to the millimeter

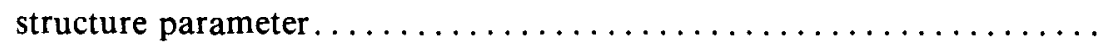




\title{
Spectral Measurements in a Disturbed Boundary Layer Over Snow
}

\author{
EDGAR L ANDREAS
}

\section{INTRODUCTION}

Atmospheric turbulence is broad-banded. In the surface layer, fluctuations in the velocity components and in the scalar atmospheric constituents occur over a continuum of frequencies from less than $1 /$ hour to well over $100 \mathrm{~Hz}$. Computing spectra and cospectra from time series of these variables separates the contributions to the total signal variance (or covariance in the case of cospectra) by frequency. Thus, spectra and cospectra provide a picture of the turbulence process. When topographic inhomogeneities perturb the atmospheric boundary layer, such representations are especially useful for examining how and at what scale the topography influences the turbulence processes.

Velocity and temperature spectra and cospectra have been measured of ten over horizontally homogeneous land surfaces (e.g., Kaimal et al. 1972, 1976, Wyngaard and Coté 1972, Tsvang et al. 1985). Humidity spectra have been measured less frequently over land (Miyake and McBean 1970, McBean 1971, Priestley and Hill 1985), because weak humidity fluctuations make the measurements difficult. Over the ocean, where fluctuations in humidity can be large, spectra of the velocity components and of the temperature and humidity have all been measured extensively (e.g., Pond et al. 1971, Leavitt 1975, Schmitt et al. 1979, Nicholls and Readings 1981, Smith and Anderson 1984).

Over snow-covered surfaces, on the other hand, spectral measurements have been rare. In fact, most spectral measurements over snow have been made over snow-covered sea ice. Banke and Smith $(1971,1973)$ and Andreas and Paulson (1979) reported velocity spectra and cospectra measured over compact Arctic sea ice; Smith et al. (1970) reported similar measurements in the Gulf of St. Lawrence. Teunissen (1980) measured spectra of the three velocity components over snow-covered ground in farming country near Toronto, Canada. Smith (1972) reported additional velocity spectra from the Gulf of St. Lawrence and included a few temperature spectra and cospectra. But only Thorpe et al. (1973) have measured both temperature and humidity spectra simultaneously over a snow-covered surface-again sea ice. Hicks and Martin (1972), MacKay and Thurtell (1978) and Yelagina et al. (1978) measured velocity, temperature and humidity fluctuations over snow-covered Lake Mendota and over snow fields in Ontario, Canada, and near Leningrad, respectively, but none reported individual spectra or cospectra, just covariance (integrals of the cospectra).

The measurements that I report here are thus, evidently, the first extensive set of turbulence spectra and cospectra measured over snow-covered ground. Although the experimental site was fairly homogeneous for a couple hundred meters around my instruments, hills typically $100 \mathrm{~m}$ high bordered the site on two sides. Hence, all the measured longitudinal $(u)$ and vertical $(w)$ velocity spectra and the temperature $(t)$ and humidity $(q)$ spectra show iner- 
tial or inertial-convective subranges typical of the horizontally homogeneous near-field but contain excess energy at low frequency because of far-field topographic disturbances. The $w-t, w-q$ and $t-q$ cospectra generally behave in the inertial-convective subrange as cospectra collected over a horizontally homogeneous surface; the $u-w$ cospectra usually have erratic sign throughout their frequency range, again suggesting just how much the topography affects the velocity field. The phase and coherence spectra corroborate the topographic effects by implying a dichotomy between low-frequency and high-frequency transfer processes.

Because I have simultaneous measurements of the $t$ and $q$ spectra and the $t-q$ cospectrum, it was possible to make theoretical computations of refractive index spectra for light of visible and millimeter wavelengths. Both sets of refractive index spectra have inertial-convective subranges. Hence, lastly, I compare refractive index structure parameters $\left(C_{n}^{2}\right)$ obtained from the spectra for visible wavelengths with simultaneous scintillometer measurements of the same quantity.

\section{MEASUREMENTS}

The turbulence data that I will report were all collected over a field near Grayling, Michigan, that was always covered with at least $30 \mathrm{~cm}$ of snow. Figure 1 shows the site; the wind vectors all terminate on the instrument mast. The snow field was basically a north-south rectangle bordered by $5-\mathrm{m}$-high pine trees. Between the instrument mast and this tree line there was about $900 \mathrm{~m}$ of field to the north, $300 \mathrm{~m}$ to the south, and $150 \mathrm{~m}$ to the west. In the northeast-to-southeast sector were instrument vans, vehicles, a few small buildings, and access roads; thus, I did not sample easterly winds. The hills in Figure 1 were also forested.

Figure 2 shows the instrument mast. The instruments for measuring the turbulent velocity, temperature and humidity fluctuations were roughly $2 \mathrm{~m}$ above the surface. I used TSI anemometers and crossed, cylindrical hot-film sensors having lengths of $1 \mathrm{~mm}$ and diameters of roughly $53 \mu \mathrm{m}$ for measuring longitudinal and vertical velocity fluctuations (Andreas and Murphy 1986b). Because these crossed sensors determine a vertical plane, it is important to keep them oriented into the wind. The instrument mast, thus, could rotate around its vertical axis so the sensors could be pointed into the wind at the start of each recording run. I have described my procedure for converting the hot-film voltage signals to $u$ and $w$ time series in an earlier publication (Andreas 1979).

For measuring the temperature fluctuations ( $t$ ), I used a platinum resistance thermometer (PRT) (LaRue et al. 1975) designed and built at CRREL. The sensor, made by DISA (now Dantec Electronics), is a $1-\mu \mathrm{m}$-diameter platinum wire $1 \mathrm{~mm}$ long. For fluctuations in absolute humidity $(q)$, I used a Lyman-alpha hygrometer also built at CRREL and based on Buck's design (Buck 1976, 1977, Buck and Post 1980). The uranium hydride source tube and the nitric oxide detector tube in this hygrometer have a separation that is variable from 0 to $10 \mathrm{~cm}$ for optimizing the response of the hygrometer to humidity fluctuations.

The mast also held a wind vane for orientation and instruments for obtaining ambient conditions at 1 and $2 \mathrm{~m}$. An R.M. Young propeller vane yielded the wind speed $\left(U_{\mathrm{pv}}\right)$ and direction $\left(\theta_{\mathrm{pv}}\right)$ at $2 \mathrm{~m}$, and a second propeller measured the wind speed at $1 \mathrm{~m}$. Two General Eastern systems measured average temperature ( $T$ ) with a rugged PRT and and absolute humidity $(Q)$ with a cooled-mirror dew-point (frost-point) hygrometer. The $T$ and $Q$ measurements at $2 \mathrm{~m}$ also allowed in situ calibration of the Lyman-alpha hygrometer.

The signals from the fast-responding sensors were passed through switched-capacitor filters with cutoff frequencies of $110 \mathrm{~Hz}$; the nominal mean of each signal was then removed, and the remaining fluctuation amplified to fill $\mathrm{a} \pm 10-\mathrm{V}$ range. All signals were then digitized at $250 \mathrm{~Hz}$ with 12-bit accuracy and written on magnetic tape. 


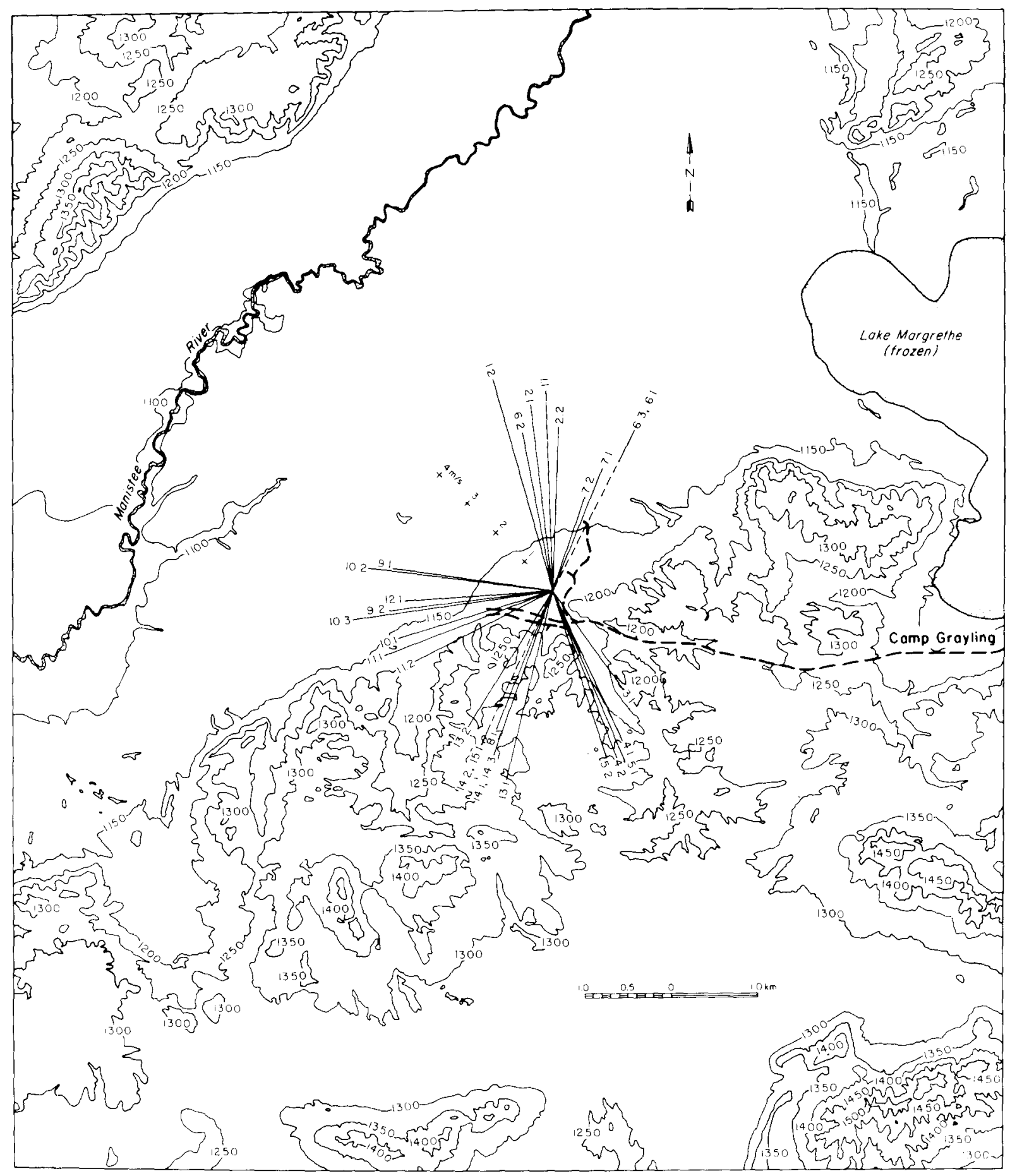

Figure 1. Topography of the experimental site. Contours are in feet. The average wind vector for each run terminates on the instrument mast. 


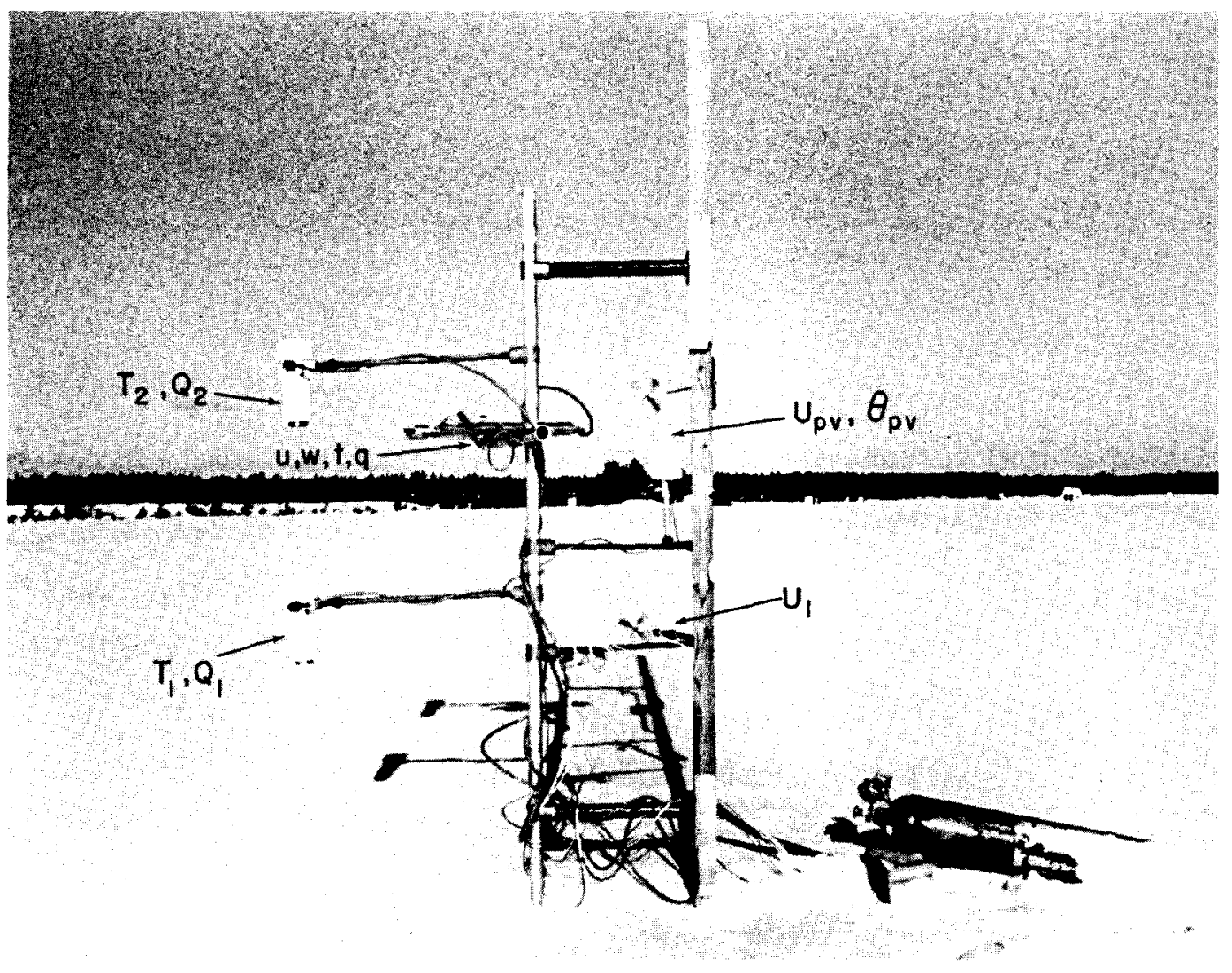

Figure 2. The instrument mast, with two levels for measuring the average quantities $\mathrm{U}, \mathrm{T}$ and $\mathrm{Q}$, and a 2-m measurement of the turbulent fluctuations $\mathrm{u}, \mathrm{w}, \mathrm{t}$ and $\mathrm{q}$.

After the experiment I screened these time series and selected for further analysis the best quality data-segments when the instruments were performing optimally, when conditions were fairly steady, and when the wind direction provided the longest fetch over smooth snow. The analysis entailed removing linear trends, computing fast Fourier transforms (FFTs) of the series in blocks of 8192 samples each, forming spectral densities from the transform coefficients, and summing the spectral densities over logarithmically spaced frequency bands. In addition, I block-averaged from 18 to 66 consecutive 8192-sample blocks (depending on the run length) to compute the final band-averaged spectral densities. By computing FFTs of the series of block averages, I also extended the spectra to lower frequencies (Pond et al. 1971).

Because few samples go into the low-frequency extension of the spectra, the spectral estimates have large uncertainties here yet contain significant energy. To reduce the contribution from these highly variable but uncertain spectral estimates, I applied a high-pass digital RC filter with a 100-s time constant (Kaimal and Haugen 1971) to all the spectra and cospectra.

During the analysis, I discovered that the filters produced significant noise near their cutoff frequency, and this, naturally, appeared in the spectra. Thus, although the raw spectral estimates should extend to the Nyquist frequency, $125 \mathrm{~Hz}$, because of this filter noise, the block- and band-averaged spectral estimates have meaningful information only to about 40 $\mathrm{Hz}$. 
Table 1. Summary of spectral runs, January 1984. The average wind speed, temperature, humidity and wind direction were measured at roughly $2 \mathrm{~m}$.

\begin{tabular}{|c|c|c|c|c|c|c|c|}
\hline \multirow[b]{2}{*}{ Run } & \multirow[b]{2}{*}{ Date } & \multicolumn{2}{|c|}{ Time (EST) } & \multirow{2}{*}{$\begin{array}{c}\mathrm{U} \\
\left(m s^{-1}\right)\end{array}$} & \multirow{2}{*}{$\begin{array}{c}\mathrm{T} \\
\left({ }^{\circ} \mathrm{C}\right)\end{array}$} & \multirow{2}{*}{$\begin{array}{c}\mathrm{Q} \\
\left(10^{-3} \mathrm{~kg} \mathrm{~m}^{-3}\right) \\
\end{array}$} & \multirow{2}{*}{$\begin{array}{c}\text { Direction } \\
\left({ }^{\circ}\right) \\
\end{array}$} \\
\hline & & Start & Stop & & & & \\
\hline 1.1 & 10 & 1058 & 1125 & 4.86 & -13.7 & 1.07 & 1 \\
\hline 1.2 & 10 & 1125 & 1152 & 5.33 & -13.3 & 0.99 & 347 \\
\hline 2.1 & 10 & 1224 & 1255 & 4.54 & -13.5 & 0.92 & 356 \\
\hline 2.2 & 10 & 1259 & 1330 & 3.98 & -13.6 & 1.10 & 5 \\
\hline 3.1 & 12 & 1027 & 1055 & 3.00 & -13.1 & 0.91 & 147 \\
\hline 4.1 & 12 & 1110 & 1146 & 4.04 & -14.6 & 1.39 & 158 \\
\hline 4.2 & 12 & 1146 & 1222 & 4.37 & -13.6 & 1.40 & 162 \\
\hline 5.1 & 12 & 1245 & 1316 & 4.56 & -11.6 & 1.41 & 160 \\
\hline 5.2 & 12 & 1321 & 1352 & 4.31 & -11.3 & 1.40 & 165 \\
\hline 6.1 & 14 & 1053 & 1108 & 4.36 & -13.6 & 1.28 & 30 \\
\hline 6.2 & 14 & 1109 & 1137 & 3.92 & -13.5 & 1.27 & 352 \\
\hline 6.3 & 14 & 1138 & 1206 & 3.49 & -13.2 & 1.24 & 30 \\
\hline 7.1 & 14 & 1225 & 1301 & 3.19 & -12.5 & 1.26 & 25 \\
\hline 7.2 & 14 & 1301 & 1337 & 2.40 & -11.9 & 1.26 & 22 \\
\hline 8.1 & 16 & 1434 & 1448 & 3.83 & -9.2 & 1.89 & 205 \\
\hline 9.1 & 17 & 1401 & 1428 & 3.96 & -9.5 & 1.26 & 281 \\
\hline 9.2 & 17 & 1429 & 1456 & 4.02 & -9.3 & 1.21 & 266 \\
\hline 10.1 & 17 & 1511 & 1526 & 3.96 & -9.5 & 1.18 & 256 \\
\hline 10.2 & 17 & 1536 & 1548 & 4.56 & -9.7 & 1.33 & 280 \\
\hline 10.3 & 17 & 1550 & 1621 & 4.93 & -9.6 & 1.25 & 265 \\
\hline 11.1 & 17 & 1629 & 1702 & 4.42 & -11.9 & 1.25 & 252 \\
\hline 11.2 & 17 & 1702 & 1728 & 3.79 & -13.2 & 1.29 & 246 \\
\hline 12.1 & 18 & 1318 & 1328 & 3.62 & -14.2 & 1.07 & 269 \\
\hline 13.1 & 21 & 1222 & 1236 & 4.75 & -17.2 & 0.90 & 197 \\
\hline 13.2 & 21 & 1239 & 1253 & 3.95 & -16.6 & 0.91 & 215 \\
\hline 14.1 & 21 & 1328 & 1338 & 4.27 & -16.7 & 0.90 & 203 \\
\hline 14.2 & 21 & 1349 & 1411 & 4.19 & -16.3 & 0.94 & 208 \\
\hline 14.3 & 21 & 1412 & 1434 & 4.26 & -15.7 & 0.96 & 203 \\
\hline 15.1 & 22 & 1423 & 1434 & 3.62 & -8.8 & 1.99 & 208 \\
\hline
\end{tabular}

Table 1 lists the experimental runs analyzed and the ambient conditions. All runs were during daylight hours, and all were from 9 to 36 minutes in duration. The snow was always at least $30 \mathrm{~cm}$ deep; its surface was usually smooth but occasionally had been sculptured into small wavelets by the wind. The upwind fetch over uniform snow depended on wind direction but was always $150-600 \mathrm{~m}$. Rarely was it snowing.

Not all runs in Table 1 yielded useful $w, t$ and $q$ time series. The delicate PRT sensor broke before or during some runs, and the Lyman-alpha hygrometer was malfunctioning during others. After seeing plots of the spectra and cospectra, I also discarded a few because their shapes were spurious.

\section{SPECTRA}

\section{$u$ and $w$ velocity spectra}

It is customary to plot spectra and cospectra nondimensionally so that spectra collected under diverse conditions will collapse into universal form. In the atmospheric surface layer, that nondimensionalization focuses on collapsing velocity spectra in the inertial subrange 
and scalar spectra in the inertial-convective subrange. Here, with the longitudinal velocity spectrum $\Phi_{\mathrm{u}}$ as an example, we expect the Kolmogorov form:

$$
\Phi_{\mathrm{u}}(k)=\alpha \epsilon^{2 / 3} k^{-5 / 3}
$$

where $k=$ turbulence wavenumber

$\epsilon=$ dissipation rate of turbulent kinetic energy

$\alpha=$ Kolmogorov constant for velocity.

Since we measure frequency rather than wavenumber spectra, we normally use Taylor's hypothesis, $k=2 \pi f / U$, where $f$ is the frequency and $U$ is the average longitudinal wind speed at the measurement height, to convert eq 1 to a nondimensional frequency spectrum (Kaimal et al. 1972):

$$
\frac{f \Phi_{\mathrm{u}}(f)}{(\epsilon z)^{2 / 3}}=\alpha(2 \pi)^{-2 / 3}(f z / U)^{-2 / 3}
$$

Thus, $f z / U$ is the nondimensional surface layer turbulence frequency, with $z$ the measurement height.

Figure 3 shows longitudinal velocity spectra made nondimensional according to eq 2 for the 29 runs listed in Table 1 . Figure 4 shows the nondimensional vertical velocity spectra. As I will explain shortly, $\epsilon$ comes from the spectral measurements via eq 2; hence the inertialsubrange collapse of the spectra in Figure 3 is somewhat artificial.

For comparison the dashed line in Figure 3 is a slightly modified version of the Kansas neutral-stability $u$ spectrum (Kaimal et al. 1972):

$$
\frac{f \Phi_{\mathrm{u}}(f)}{(\epsilon z)^{2 / 3}}=53.9 \frac{f z / U}{[1+33(f z / U)]^{5 / 3}} .
$$

Although eq 3 has a slightly different form than the equation given by Kaimal et al. (1972, eq $21 a$ ), the only real difference is that eq 3 represents an $\alpha$ value of 0.54 (Williams and Paulson 1977, Antonia et al. 1981) instead of the value of 0.52 that their equation implies. The dashed line in Figure 4 is

$$
\frac{f \Phi_{w}(f)}{(\epsilon z)^{2 / 3}}=1.12 \frac{f z / U}{\left[1+5.3(f z / U)^{5 / 3}\right]}
$$

a modified version of the Kansas neutral-stability $w$ spectrum (Kaimal et al. 1972, eq 21c). Equation 4 is different from the form given by Kaimal et al. (1972) in that it also reflects an $\alpha$ value of 0.54 , and the multiplicative constant on the right side is adjusted so that $\Phi_{\mathrm{w}} / \Phi_{\mathrm{u}}=$ $4 / 3$ at large $f$, as required by isotropy. The equations given by Kaimal et al. (1972) yield $\Phi_{\mathbf{w}} / \Phi_{\mathbf{u}}=1.22$ at large $f$.

Neutral-stability Kansas spectra and cospectra are appropriate for comparing with my spectra and cospectra because, as I will show shortly, all 29 runs in Table 1 were made in near-neutral stability: the stability parameter $z / L$, where $L$ is the Obukhov length, was always between -0.01 and 0.05 . With a measurement height of $2 \mathrm{~m}$, all spectra were collected in the "inner region" defined by Jackson and Hunt (1975).

The spectra in Figures 3 and 4 collapse well into common shapes, especially in the inertial subrange. The scatter in the spectra at low frequency is a consequence of both the statistical uncertainty in the spectral estimates at these frequencies and the inherent variability in the horizontal wind at these scales. 


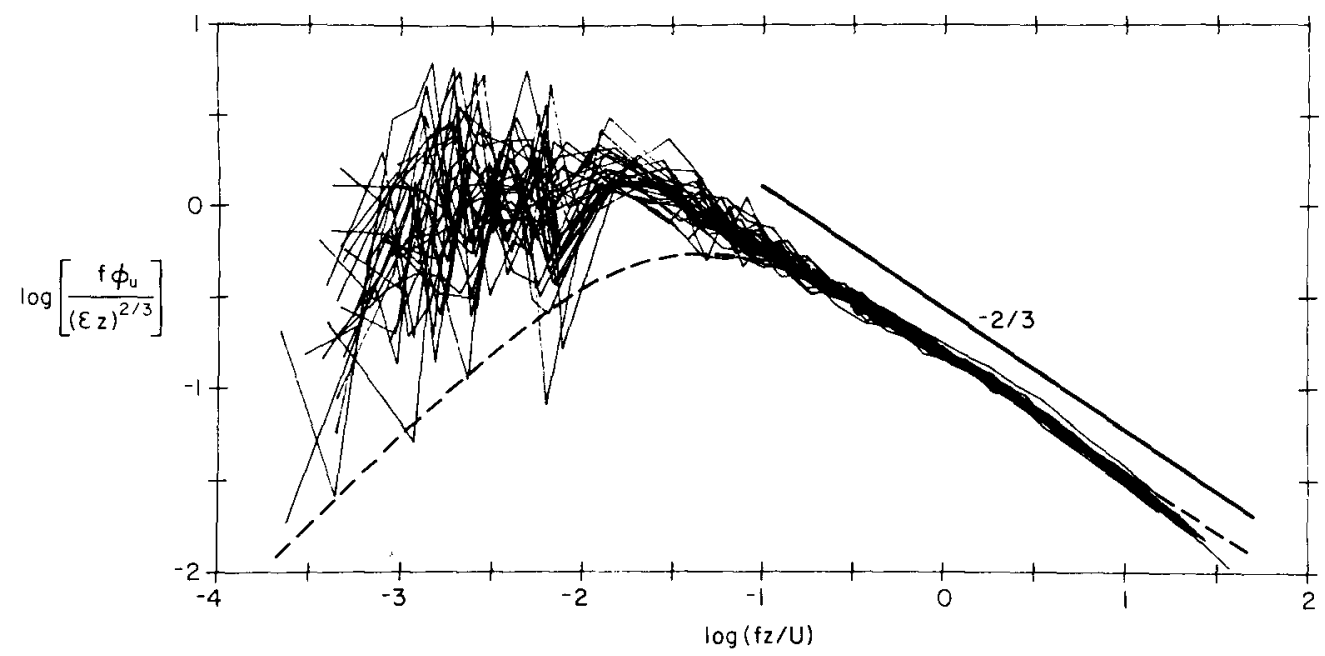

Figure 3. Nondimensional $\mathrm{u}$ velocity spectrum for each run in Table 1. The dashed line is the Kansas neutral-stability u spectrum (eq 3).

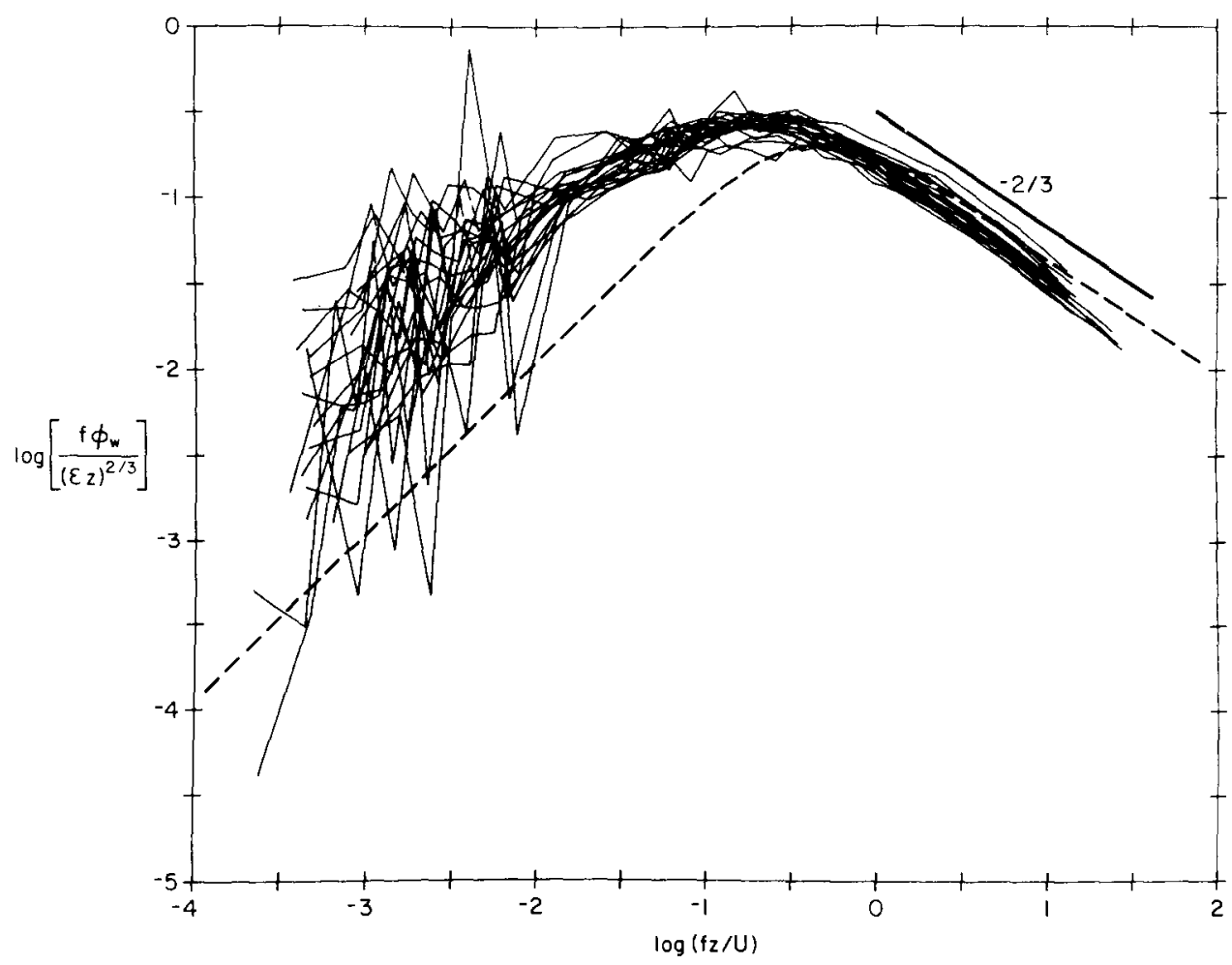

Figure 4. Twenty-two nondimensional $\mathrm{w}$ velocity spectra. The dashed line is the Kansas neutral-stability w spectrum (eq 4). 
These collected spectra are different in two ways from the Kansas spectra, which were collected over a horizontally homogeneous surface. They have much more energy at low frequency, and the inertial subrange starts at a nondimensional frequency that is roughly a decade lower than in the Kansas spectrum. The topography is responsible for both conditions. Whether the wind was coming down from the hills or being dammed as it flowed up over them (Fig. 1), the effect was the same-to induce fluctuations in the vertical velocity. Because of mass continuity and pressure correlations, these vertical velocity fluctuations created fluctuations in the other two velocity components at a scale roughly that of the topography. In both Figures 3 and 4 the maximum difference between the measured and the Kansas spectra occurs for $\log (f z / U)$ between -2 and -1.5 ; with $z=2 \mathrm{~m}$, this implies that the eddies responsible for this energy had wavelengths of $60-100 \mathrm{~m}$, about the height of the hills above the snow field. It is obvious from Figure 1 that there are a host of other longer and shorter length scales associated with the topography, but the height of the hills is the simplest and the one most clearly represented in the velocity spectra (e.g., Jackson and Hunt 1975).

The second difference in my spectra, the extended inertial subrange, is likewise a consequence of the topography. Because of the topographic energy generation, the spectral peaks in Figures 3 and 4 appear at lower frequencies than in the Kansas spectra. In other words, because of the topography, the energy-containing or energy-producing region is shifted to longer length scales, thereby increasing the spectral separation between the production and dissipation regions. The inertial subrange can, therefore, begin at a proportionately lower nondimensional frequency (Tennekes and Lumley 1972, p. 264ff.).

Although a few measurements of velocity spectra exist for complex terrain, the terrain at this site was more complex than most. Not only was there a series of hills, rather than the isolated hill commonly studied (Jackson and Hunt 1975, Bradley 1980, Smedman and Bergstrom 1984, Mason and King 1985), the surface roughness $\left(z_{0}\right)$ of the site was small $(\sim 0.1-1$ $\mathrm{cm})$ (Banke et al. 1980) over the near-field snow but relatively large ( $\sim 0.2-0.5 \mathrm{~m})$ (Garratt 1977) over the wooded hills and the woods surrounding the snow field. My velocity spectra, nevertheless, show some of the same trends seen by others.

For example, though Smedman and Bergstrom (1984) made measurements at the summit of a fairly low, isolated hill, their velocity spectra from the inner region collected under nearneutral stability had characteristics like mine. Both their $u$ and $w$ spectra behaved as $f^{-5 / 3}$ at high frequency, with $\Phi_{w}$ somewhat lower than the Kansas neutral-stability spectrum here, like my $w$ spectra (Fig. 4). At low frequency, their $u$ and $w$ spectra contained more energy than the Kansas spectra though not as much excess energy as mine do, perhaps because their hill was only $20 \mathrm{~m}$ above the surrounding terrain.

Mason and King (1985) measured $u$ and $w$ spectra in neutral stability conditions within the inner region at the summit and near the base of an isolated, $100-\mathrm{m}$-high hill-a height typical of the topography for this study. They, too, found excess energy at low frequency compared to the Kansas spectra for both velocity components and at both locations. At high frequency, however, both $u$ and $w$ spectra rolled off faster than $f^{-5 / 3}$. In an earlier study of flow over ridges and valleys using basically the same instruments, Mason and King (1984), however, did find $f^{-5 / 3}$ behavior in both $u$ and $w$ spectra at a ridge crest and on the valley floor. And again they found excess energy in $\Phi_{u}$ and $\Phi_{w}$ at low frequency, with spectra from the valley floor containing more energy than spectra from the ridge crest.

Teunissen (1980) measured spectra of the three velocity components under near-neutral conditions over relatively flat, snow-covered terrain studded with occasional trees, fences and farm buildings. Like mine, his spectra showed more energy than the Kansas neutralstability velocity spectra; he attributed this to the rough terrain at his site. Teunissen also noticed that the low-frequency behavior of his spectra made them look more like Kansas spectra collected in unstable conditions. He, however, discounted the notion that unstable stratification higher in the boundary layer affected his spectra, because during his experiment the boundary layer had slightly stable stratification. $\mathrm{He}$, thus, reiterated his conclusion that the 
roughness of his site, not the stratification, led to the excess low-frequency energy. I can make a similar argument. Radiosondes released during our experiment typically showed an inversion layer to no higher than $300 \mathrm{~m}$, with a well-mixed layer usually above this. Thus, although the surface layer was nearly neutral, conditions higher up were slightly stable; therefore, the excess energy I find at low frequency in the velocity spectra cannot be a consequence of unstable stratification above the surface layer.

At the Boulder Atmospheric Observatory (BAO), a site with much gentler local relief than mine, Kaimal et al. (1982) measured velocity spectra in unstable conditions that were much the same as the Kansas spectra. The only differences they noted were that the BAO $w$ spectra had peaks shifted to somewhat lower frequency, and consequently these spectra contained slightly more energy at low frequency than $w$ spectra collected over horizontally homogeneous terrain. At BAO in stable conditions, on the other hand, Hunt et al. (1985) saw the effects of topographically induced internal gravity waves at low frequency in $w$ spectra collected near the surface. At high frequency the inertial subrange seemed unaffected.

In summary, my measured $u$ and $w$ spectra are consistent with most other velocity spectra measured in the inner region over complex terrain. Both $u$ and $w$ spectra have extensive inertial subranges where the small scales have come rapidly to equilibrium with the underlying surface and the turbulence seems locally isotropic (Panofsky et al. 1982, Mason and King 1985). At lower frequency, in near-neutral stability, the topography is responsible for increasing the energy content in both velocity components compared to spectra obtained over horizontally homogeneous surfaces.

\section{Temperature and humidity spectra}

At large Reynolds numbers an inertial-convective subrange should exist in scalar spectra where, with the temperature spectrum $\Phi_{t}$ as an example (Corrsin 1951, Phelps and Pond 1971, Tennekes and Lumley 1972),

$$
\Phi_{\mathrm{t}}(k)=\beta_{\mathrm{t}} N_{\mathrm{t}} \epsilon^{-1 / 3} k^{-5 / 3} .
$$

Here $\beta_{\mathrm{t}}$ is the Kolmogorov constant for temperature, and $N_{\mathrm{t}}$ is the dissipation rate of half the temperature variance. Because the velocity field advects scalar contaminants, however, we would expect scalar spectra to mirror the energy levels of velocity spectra at low frequency. Despite low temperatures, a frozen surface and near-neutrality in the surface layer, Figures 5 and 6 show that the turbulent temperature and humidity fields during the experiment contained enough energy to yield excellent spectra. And both spectral sets have the expected features-an inertial-convective subrange and high energy at low frequency.

The dashed line in both figures is a modified version of the Kansas neutral-stability temperature spectrum (Kaimal et al. 1972),

$$
\begin{aligned}
\frac{f \Phi_{\mathrm{t}}(f)}{N_{\mathrm{t}} \epsilon^{-1 / 3} z^{2 / 3}} & =34.8 \frac{f z / U}{[1+24(f z / U)]^{5 / 3}}, \quad f z / U \leq 0.15, \\
& =15.9 \frac{f_{z} / U}{[1+12.5(f z / U)]^{5 / 3}}, \quad f z / U \geq 0.15 .
\end{aligned}
$$

Although this form looks different from eq $21 \mathrm{~d}$ in Kaimal et al. (1972), the only essential differences are that eq 6 reflects the more commonly accepted ratio for the turbulent diffusivities for heat $\left(K_{\mathrm{H}}\right)$ and momentum $\left(K_{\mathrm{M}}\right)$ at neutral stability of $K_{\mathrm{H}} / K_{\mathrm{M}}=1$ rather than the value 0.74 used by them, and it implies $\beta_{\mathrm{t}}=0.80$ instead of the value 0.82 implicit in their equation. 


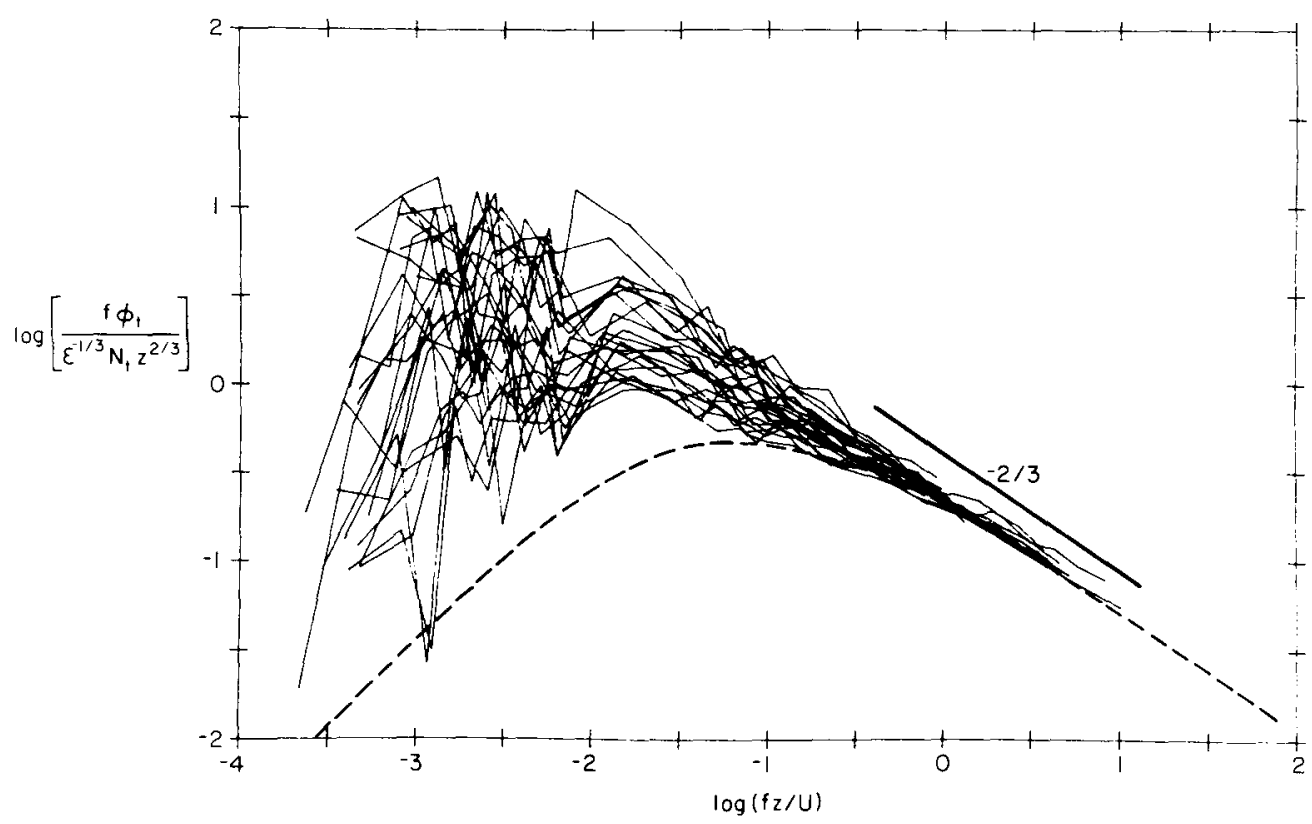

Figure 5. Twenty-four nondimensional temperature spectra. The dashed line is the Kansas neutral-stability temperature spectrum (eq 6).

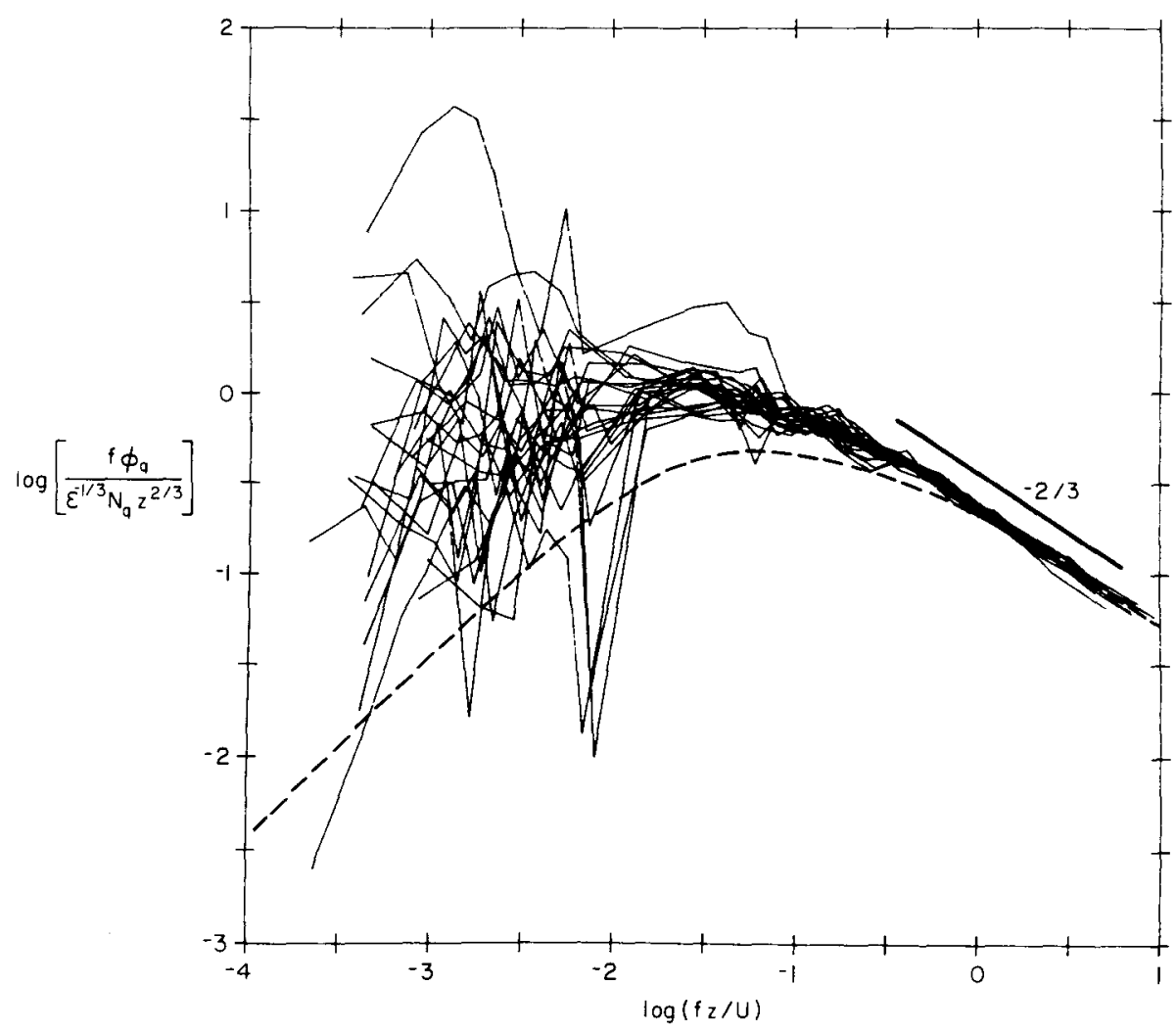

Figure 6. Twenty-four nondimensional humidity spectra. The dashed line is the Kansas neutral-stability temperature spectrum (eq 6). 
The dashed line in Figure 6 is also given by eq 6, since Kaimal et al. (1972) measured no humidity spectra. In Figure 6 the absolute humidity spectrum, $\Phi_{\mathrm{q}}$, is made nondimensional with $N_{\mathrm{q}}$, the dissipation rate of half the humidity variance. Notice that in using eq 6 to also represent humidity, I am assuming that the Kolmogorov constant for humidity, $\beta_{\mathrm{q}}$, is equal to $\beta_{\mathrm{t}}, \beta_{\mathrm{t}}=\beta_{\mathrm{q}}=\beta=0.80$, as many measurements have suggested (Paquin and Pond 1971, Wyngaard and Coté 1971, Champagne et al. 1977, Raupach 1978, Wyngaard et al. 1978, Bradley et al. 1981, Large and Pond 1982).

As anticipated, at high frequency the collected temperature and humidity spectra in Figures 5 and 6 have the $f^{-5 / 3}$ behavior indicative of an inertial-convective subrange. At low frequency, although stability conditions were nearly neutral, the scalar spectra contain roughly an order of magnitude more energy than predicted by the Kansas measurements. This excess energy is presumably again a consequence of the topography; large-scale, topographically induced velocity fluctuations simply advect the imbedded scalar field, giving it spectral characteristics similar to the longitudinal velocity spectrum. With this excess spectral energy at low frequency, the energy-producing or energy-containing region of the scalar spectra is shifted to lower frequencies, as noted with the velocity spectra. Hence, the inertial-convective subrange seems to start at lower frequency in the measured $t$ and $q$ spectra than in the Kansas spectrum.

Because these temperature and humidity spectra have similar shapes, it is reasonable to compare both to the Kansas temperature spectrum (Schmitt et al. 1979). The only obvious difference between the nondimensional spectra is that the $t$ spectra generally contain slightly more energy at low frequency than the $q$ spectra. Consequently the peaks in the $t$ spectra are near $\log (f z / U)=-2.3$, while for the $q$ spectra they are roughly at $\log (f z / U)=-1.7$.

Rarely have simultaneous measurements of temperature and humidity fluctuations yielded such compatible spectral sets. Most simultaneous $t$ and $q$ measurements have been made over the ocean. Phelps and Pond (1971) found significant differences between temperature and humidity spectra measured during BOMEX (Barbados Oceanographic and Meteorological Experiment) and again over the ocean near San Diego. In particular, their BOMEX $t$ spectra had no inertial-convective subrange. Nicholls and Readings (1981) also observed different spectral forms for temperature and humidity obtained from an aircraft flying in the surface layer above the ocean. Their humidity spectra were generally compatible with the Kansas temperature spectra; but, although their $t$ spectra showed an inertial-convective subrange, they had local minima where the neutral-stability Kansas spectrum had its peak. Leavitt's (1975) $t$ and $q$ spectra from BOMEX had similar inertial-convective subrange behavior, but his $q$ spectra generally had much more energy at low frequency than his $t$ spectra. Friehe et al. (1975) found similar $t$ and $q$ spectra over the freshwater Salton Sea; but over the ocean southwest of San Diego, their measured $q$ spectra had an extensive inertial-convective subrange, while their $t$ did not. Schmitt et al. (1979) measured humidity spectra in the North Pacific that generally looked like the Kansas temperature spectra except for an unexplained hump near $f z / U=1$ and excess energy at low frequency in stable conditions, which they attributed to instrument problems. Their temperature spectra, however, were anomalous. These latter measurements and those by Friehe et al. (1975) help explain some of the more conspicuous differences between observed over-ocean temperature and humidity spectra. Sea salt particles can contaminate small, fast-responding temperature sensors by making them also responsive to humidity fluctuations (Schmitt et al. 1978, 1979, Fairall et al. 1979). Spurious temperature spectra often result.

No similar complications exist, of course, with over-land turbulence measurements. Over land, however, humidity fluctuations may be so small that only sensors with very low noise can resolve $q$ spectra. For example, McBean's (1971) temperature spectra showed a distinct inertial-convective subrange; but his humidity spectra, though having levels similar to his $t$ 
spectra at low frequency, fell off much more rapidly than $f^{-5 / 3}$ at high frequency. Kohsiek (1984) made similar observations; his $t$ spectra went as $f^{-5 / 3}$ at high frequency, but his $q$ spectra fell of fomewhat more rapidly. The temperature and humidity spectra Schmitt et al. (1979) measured over Minnesota farmland behaved, generally, like the Kansas temperature spectra; but, as with their oceanic measurements, the humidity spectra had an unusual hump near $f z / U=1$. Although the spectra measured by Priestley and Hill (1985) did not extend to frequencies below the spectral peak, their temperature and humidity spectra, like mine, showed a distinct inertial-convective subrange that seemed to begin at frequencies lower than suggested by the Kansas spectra. The $t$ and $q$ spectra that Ohtaki (1985) measured over vegetated fields in Japan also had an inertial-convective subrange; but his $t$ spectra had somewhat more low-frequency energy than his $q$ spectra, as with my spectra.

The only other temperature and humidity spectra measured over snow that I know of, those by Thorpe et al. (1973) from the Beaufort Sea, are dissimilar. Their humidity spectra generally had an inertial-convective subrange, but their temperature spectra did not because of an inadequacy in their temperature sensor. At low frequency their temperature spectra had slightly more energy than their humidity spectra, as mine do.

Very few measurements of scalar spectra have been made over complex terrain. At the Boulder Atmospheric Observatory, where the terrain is gently rolling, Kaimal et al. (1982) found no essential differences between measured temperature spectra and the Kansas spectra for unstable conditions. In stable conditions at the same site, however, Hunt et al. (1985) saw evidence at low frequency in their temperature spectra of internal gravity waves that they imply were topographically induced.

To summarize, my measured temperature and humidity spectra are comparable with other measured scalar spectra. Their main distinguishing feature is the excess energy at low frequency, a consequence of the topographically induced velocity fluctuations at these scales. Because of this excess energy, the spectral production region is at lower frequency than in spectra collected over a horizontally homogeneous surface; hence, the inertial-convective subrange begins at lower frequency. This, too, has been observed before. That $t$ spectra have somewhat more low-frequency energy than $q$ spectra is not a hard-and-fast rule but also has been seen before.

\section{INERTIAL-DISSIPATION ESTIMATES}

With spectral measurements of velocity and scalar fluctuations that show inertial or inertial-convective subranges, it is reasonable to compute inertial-dissipation estimates of the turbulent momentum $(\tau)$ and sensible $\left(H_{\mathrm{S}}\right)$ and latent $\left(H_{\mathrm{L}}\right)$ heat fluxes:

$$
\begin{aligned}
& \tau=-\varrho \overline{u w}=\varrho u_{*}^{2} \\
& H_{\mathrm{s}}=\varrho c_{\mathrm{p}} \overline{w t}=-\varrho c_{\mathrm{p}} u_{*} t_{*} \\
& H_{\mathrm{L}}=L_{\mathrm{s}} \overline{w q}=-L_{\mathrm{s}} u_{*} q_{*}
\end{aligned}
$$

where

$$
\varrho=\text { air density }
$$

$c_{\mathrm{p}}=$ specific heat of air at constant pressure

$L_{\mathrm{s}}=$ latent heat of sublimation of ice

$u_{*}, t_{*}$ and $q_{*}=$ velocity, temperature and humidity scales defined as shown and an overbar indicates a time average. 
The inertial-dissipation technique starts with budget equations for the turbulent kinetic energy and for the scalar variances. Fairall and Larsen (1986) discussed these equations and explained simplifications that make them tractable. For kinetic energy the budget equation seems to involve different terms depending on whether conditions are stable or unstable; but, for conditions near neutral, all of the equations reduce essentially to a balance between production and dissipation. Specifically,

$$
\begin{aligned}
& \left(u_{*}^{3} / \varkappa z\right)\left[\phi_{\mathrm{m}}(z / L)-z / L\right]=\epsilon \\
& {\left[(\overline{w t})^{2} / u_{*} \varkappa z\right] \phi_{\mathrm{h}}(z / L)=N_{\mathrm{t}}} \\
& {\left[(\overline{w q})^{2} / u_{*} \varkappa z\right] \phi_{\mathrm{h}}\left(z / L_{\mathrm{Q}}\right)=N_{\mathrm{q}}}
\end{aligned}
$$

where $\varkappa=$ von Kármán's constant $(0.4)$

$\phi_{\mathrm{m}}=$ dimensionless longitudinal velocity gradient

$\phi_{\mathrm{h}}=$ dimensionless scalar gradient.

Large and Pond $(1981,1982)$ used these same equations for all stabilities. It is customary to assume that $\phi_{\mathrm{h}}$ has the same form for both potential temperature and absolute humidity (Fairall and Larsen 1986), since this gradient function has rarely been measured for humidity (Dyer 1974, Dyer and Bradley 1982). Notice, however, in eq 11 and 12, I use different stability parameters for temperature and humidity:

$$
\begin{gathered}
L_{\mathrm{Q}}=-\left[\begin{array}{ll}
\frac{g \varkappa}{u_{*}^{3}} & \frac{0.61 \overline{w q}}{\varrho+0.61 \bar{Q}}
\end{array}\right]^{-1} \\
L=\left[\begin{array}{ll}
-\frac{g \varkappa}{u_{*}^{3} \bar{T}} \overline{w t}+L_{\mathrm{Q}}^{-1}
\end{array}\right]^{-1}
\end{gathered}
$$

where $L$ is the usual Obukhov length corrected for moisture flux, and $L_{\mathrm{Q}}$ is a length scale based on the moisture flux alone (Busch 1973). $\bar{T}$ and $\bar{Q}$ are representative surface layer values of potential temperature and absolute humidity. Later, we will see that the temperature and humidity fluctuations were seldom positively correlated for the measurements reported here. McBean (1971) explained that unless a passive scalar contaminant is well correlated with temperature, $L$ is not the proper scaling length for it. Rather, a length scale based only on the flux of the scalar, such as $L_{\mathrm{Q}}$ is for humidity, is a more meaningful parameter (Andreas and Makshtas 1985).

A plethora of forms for $\phi_{\mathrm{m}}$ and $\phi_{\mathrm{h}}$ exists in the literature (e.g., Dyer 1974, Yamamoto 1975, Yaglom 1977). The representations I use in eq 10-12 are the same ones that Large and Pond (1982) used:

for unstable conditions $\left(z / L, z / L_{\mathrm{Q}}<0\right)$,

$$
\begin{aligned}
& \phi_{\mathrm{m}}(z / L)=[1-16(z / L)]^{-1 / 4} \\
& \phi_{\mathrm{h}}(z / L)=[1-16(z / L)]^{-1 / 2} \\
& \phi_{\mathrm{h}}\left(z / L_{\mathrm{Q}}\right)=\left[1-16\left(z / L_{\mathrm{Q}}\right)\right]^{-1 / 2}
\end{aligned}
$$


for stable conditions $\left(z / L, z / L_{\mathrm{Q}}>0\right)$,

$$
\begin{aligned}
& \phi_{\mathrm{m}}(z / L)=\phi_{\mathrm{h}}(z / L)=1+7(z / L) \\
& \phi_{\mathrm{h}}\left(z / L_{\mathrm{Q}}\right)=1+7\left(z / L_{\mathrm{Q}}\right) .
\end{aligned}
$$

The method of estimating $\epsilon, N_{\mathrm{t}}$ and $N_{\mathrm{q}}$ for use in eq 10-12 defines the inertial-dissipation method. I found $\epsilon$ from measurements of $\Phi_{\mathrm{u}}$ in the inertial subrange using eq 1 with $\alpha=$ 0.54 . Similarly, knowing $\epsilon$ now, I found $N_{\mathrm{t}}$ and $N_{\mathrm{q}}$ from measurements of $\Phi_{\mathrm{t}}$ and $\Phi_{\mathrm{q}}$ in the inertial-convective subrange using eq 5 for temperature,

$$
\Phi_{\mathrm{q}}(k)=\beta_{\mathrm{q}} N_{\mathrm{q}} \epsilon^{-1 / 3} k^{-5 / 3}
$$

for humidity, and with $\beta_{\mathrm{t}}=\beta_{\mathrm{q}}=0.80$. Having these values, I iteratively solved eq 10-12 for $u_{*}, \overline{w t}$ and $\overline{w q}$.

Notice that eq 11 and 12 cannot yield the signs of $\overline{w t}$ and $\overline{w q}$. To determine these I looked at the inertial-subrange behavior of the $w-t$ and $w-t$ cospectra and at the difference between temperatures and humidities measured at the snow surface and at $2 \mathrm{~m}$. The surface temperature and humidity measurements were based on a newly developed hygrometric technique (Andreas 1986).

Although all of the computations involved in the inertial-dissipation technique are formally possible because $\Phi_{\mathrm{u}}, \Phi_{\mathrm{t}}$ and $\Phi_{\mathrm{q}}$ have $f^{-5 / 3}$ regions, I must nevertheless discuss their theoretical justification. The assumptions that went into eq 10-12 are that the surface is horizontally homogeneous - thus, advection is unimportant - and that turbulent transport is negligible (Fairall and Larsen 1986). Even if the turbulent transport, which has never been investigated over complex terrain, is negligible, we have already seen how advection of the scalar fields by the topographically disturbed velocity field affects the spectra. But these effects were confined to long wavelengths-wavelengths typical of the topography. Thus, as Panofsky et al. (1982) and Mason and King (1985) suggested, over complex terrain the small-scale turbulence still rapidly reaches equilibrium with the local surface. Hence, eq 1, 5 and 20 should yield fairly accurate estimates of $\epsilon, N_{\mathrm{t}}$ and $N_{\mathrm{q}}$. Although horizontal homogeneity is also the basis for the flux-gradient representation of the vertical profiles- $\phi_{\mathrm{m}}(z / L), \phi_{\mathrm{h}}(z / L)$ and $\phi_{\mathrm{h}}\left(z / L_{\mathrm{Q}}\right)$ in eq 10-12-Smith et al. (1983) and Andreas and Murphy (1986a) have recently shown that the functions (eq 15-19) are accurate and useful even over extremely inhomogeneous surfaces. Consequently, in light of our need for estimates of the turbulent fluxesbut keeping the possible shortcomings of eq 10-12 in mind-it seems justifiable to base rough estimates of the fluxes on eq 10-12.

Table 2 lists the results of the inertial-dissipation calculations. A positive flux is upwardfrom the snow into the air. Where there are blanks in the table, the temperature or humidity spectrum was unavailable; to make the calculations for these runs, I assumed that the corresponding dissipation rate was zero. This assumption had little effect on the resulting values since the heat fluxes were so small and the absolute values of $L$ and $L_{\mathrm{Q}}$ were so large.

Table 2 shows that stability conditions were nearly neutral: $z / L$ was always between -0.01 and 0.05 . The heat fluxes $H_{\mathrm{s}}$ and $H_{\mathrm{L}}$ were small, with absolute values seldom above $10 \mathrm{~W}$ $\mathrm{m}^{-2}$. This is not surprising, considering the gentle winds (Table 1) and the heat fluxes over snow and snow-covered sea ice that others have measured (Hicks and Martin 1972, Thorpe et al. 1973, McKay and Thurtell 1978, Yelagina et al. 1978, Andreas and Makshtas 1985). One interesting result evident in Table 2 is that $H_{\mathrm{s}}$ and $H_{\mathrm{L}}$ generally had opposite signs. Even during daylight hours $H_{\mathrm{s}}$ was usually downward, while $H_{\mathrm{L}}$ was predominantly upward. That is, the air was usually losing sensible heat to the surface but was recouping some of this loss as 
Table 2. Inertial-dissipation estimates of the fluxes.

\begin{tabular}{|c|c|c|c|c|c|c|}
\hline Run & $\mathrm{z} / \mathrm{L}$ & $\begin{array}{c}\mathrm{L} \\
(m)\end{array}$ & $\begin{array}{l}\mathrm{L}_{Q} \\
(m)\end{array}$ & $\begin{array}{c}\mathrm{u} . \\
\left(m s^{-1}\right)\end{array}$ & $\begin{array}{c}\mathbf{H}_{s} \\
\left(W m^{-2}\right)\end{array}$ & $\begin{array}{c}\mathbf{H}_{L} \\
\left(W m^{-2}\right) \\
\end{array}$ \\
\hline 1.1 & 0.011 & 190 & -9800 & 0.27 & -9.5 & 3.1 \\
\hline 1.2 & 0.008 & 250 & -8900 & 0.28 & -7.8 & 3.8 \\
\hline 2.1 & 0.011 & 180 & -6400 & 0.24 & -7.0 & 3.3 \\
\hline 2.2 & 0.017 & 120 & -4000 & 0.20 & -6.5 & 3.4 \\
\hline 3.1 & -0.005 & -390 & -11000 & 0.19 & 1.6 & 1.0 \\
\hline 4.1 & -0.003 & -600 & -5000 & 0.21 & 1.2 & 3.0 \\
\hline 4.2 & 0.003 & 610 & -4600 & 0.21 & -1.5 & 3.2 \\
\hline 5.1 & 0.003 & 680 & -3400 & 0.24 & -2.1 & 6.1 \\
\hline 5.2 & 0.003 & 750 & -3000 & 0.23 & -1.7 & 5.9 \\
\hline 6.1 & 0.017 & 120 & & 0.19 & -5.4 & \\
\hline 6.2 & 0.022 & 92 & & 0.18 & -5.9 & \\
\hline 6.3 & 0.022 & 91 & & 0.17 & -4.9 & \\
\hline 7.1 & 0.027 & 72 & & 0.14 & -3.6 & \\
\hline 7.2 & 0.050 & 40 & & 0.11 & -3.2 & \\
\hline 8.1 & & & -5200 & 0.23 & & 3.5 \\
\hline 9.1 & 0.004 & 490 & -4300 & 0.22 & -2.3 & 4.1 \\
\hline 9.2 & 0.005 & 360 & -3800 & 0.21 & -2.6 & 3.9 \\
\hline 10.1 & 0.006 & 330 & -3600 & 0.22 & -2.9 & 4.4 \\
\hline 10.2 & 0.003 & 610 & -6600 & 0.25 & -2.5 & 3.7 \\
\hline 10.3 & 0.007 & 270 & -5000 & 0.26 & -5.9 & 5.3 \\
\hline 11.1 & 0.015 & 130 & -19000 & 0.22 & -7.7 & 0.9 \\
\hline 11.2 & 0.026 & 74 & 6400 & 0.20 & -8.9 & -1.9 \\
\hline 12.1 & -0.005 & -430 & -3400 & 0.21 & 1.6 & 4.1 \\
\hline 13.1 & -0.008 & -240 & -33000 & 0.27 & 7.5 & 1.0 \\
\hline 13.2 & 0.013 & 150 & -24000 & 0.26 & -10.2 & 1.2 \\
\hline 14.1 & -0.010 & -190 & -15000 & 0.26 & 8.1 & 1.8 \\
\hline 14.2 & & & -16000 & 0.26 & & 1.7 \\
\hline 14.3 & & & -16000 & 0.27 & & 1.9 \\
\hline 15.1 & & & -5000 & 0.22 & & 3.3 \\
\hline
\end{tabular}

latent heat from surface sublimation. Most other measurements of $H_{\mathrm{L}}$ over a snow-covered surface have also shown the predominance of sublimation over condensation (McKay and Thurtell 1978, Yelagina et al. 1978, Andreas and Makshtas 1985).

The next section discusses measurements of the $w-t$ and $w-q$ cospectra. Integrals of these cospectra yield eddy-correlation estimates of $H_{\mathrm{S}}$ and $H_{\mathrm{L}}$. Although these eddy-correlation estimates are broadly compatible with the inertial-dissipation estimates of $H_{\mathrm{s}}$ and $H_{\mathrm{L}}$, they have much more scatter because of large but statistically uncertain contributions to the integrals from the low-frequency end of the cospectra. Hence, the inertial-dissipation estimates of the fluxes are more useful, especially for nondimensionalizing the cospectra.

\section{COSPECTRA}

With simultaneous $u, w, t$ and $q$ time series, it is possible to compute cospectra $\left(\mathrm{Co}_{\mathrm{xy}}\right)$ and quadrature spectra $\left(Q d_{\mathrm{xy}}\right)$ of any two variables $x$ and $y$. The cospectra, individually, are interesting; but since the quadrature spectra contain basically phase information, they are most useful for defining phase and coherence spectra. If $\Phi_{x}$ and $\Phi_{y}$ are spectra of $x$ and $y$ fluctuations, the phase and coherence spectra are defined, respectively, as

$$
\Theta_{\mathrm{xy}}(f)=\arctan \left[Q d_{\mathrm{xy}}(f) / C o_{\mathrm{xy}}(f)\right]
$$




$$
C h_{\mathrm{xy}}(f)=\frac{C o_{\mathrm{xy}}(f)^{2}+Q d_{\mathrm{xy}}(f)^{2}}{\Phi_{\mathrm{x}}(f) \Phi_{\mathrm{y}}(f)}
$$

The phase spectrum gives the phase lag between simultaneous fluctuations in $x$ and $y$. The coherence spectrum is like a spectral correlation coefficient: high values of $C h_{\mathrm{xy}}$ mean $x$ and $y$ have good positive or negative correlation; low values mean they are poorly correlated. Through most of the spectrum, $C h_{\mathrm{xy}} \leq 1.0$ (Panofsky and Dutton 1984, p. 73). But because of the averaging used in the extended portion of my spectra and cospectra, $C h_{\mathrm{xy}}$ can be greater than one here as a consequence of the statistical variability in these low-frequency estimates.

Notice that the phase and coherence spectra allow alternative definitions of the cospectrum and the quadrature spectrum:

$$
\begin{aligned}
& \operatorname{Co}_{\mathrm{xy}}(f)=\left|G_{\mathrm{xy}}(f)\right| \cos \left[\Theta_{\mathrm{xy}}(f)\right] \\
& Q d_{\mathrm{xy}}(f)=\left|G_{\mathrm{xy}}(f)\right| \sin \left[\Theta_{\mathrm{xy}}(f)\right]
\end{aligned}
$$

where

$$
\left|G_{\mathrm{xy}}(f)\right|=\left[\Phi_{\mathrm{x}}(f) \Phi_{\mathrm{y}}(f) C h_{\mathrm{xy}}(f)\right]^{1 / 2} .
$$

Thus, the quadrant in which the phase spectrum lies is directly related to the signs of the cospectrum and quadrature spectrum.

\section{$u-w$ cospectra}

The $u-w$ cospectral plots show best the effects of the topography on the surface boundary layer at our site. Figure 7 a contains $u-w$ cospectra plotted nondimensionally with typical surface-layer scaling (Kaimal et al. 1972) for the 29 runs in Table 1. The vacillating sign of the cospectral estimates at both high and low frequency is obvious. Over a horizontally homogeneous surface, $\mathrm{Co}_{\mathrm{uw}}$ would be uniformly negative-the wind transferring momentum downward to the surface at all scales. The variability in Figure 7a implies, however, that at some scales the air was transferring momentum downward, while at other scales the transfer was upward. The $u-w$ phase and coherence spectra (Fig. $7 \mathrm{~b}$ and c) show similarly confused pictures. $\Theta_{\mathrm{uw}}$ and $C h_{\mathrm{uw}}$ can have virtually any values at low frequency. That is, sometimes $u$ and $w$ were fairly well correlated here, but at other times they were poorly correlated. At high frequency, $\Theta_{u w}$ is generally between $0^{\circ}$ and $180^{\circ}$ and $C h_{u w}$ decreases to zero. Therefore, in the inertial subrange the $u$ fluctuations often led the $w$ fluctuations but seldom by enough to make $\mathrm{Co}_{\mathrm{uw}}$ negative.

Others have observed sign reversals in $u-w$ cospectra or in time series of the product $u w$; but rarely have these been as prevalent as in Figure 7a. Smith et al. (1970), for example, found a few positive cospectral values at the lowest frequencies in their measurements near the surface of broken sea ice in the Gulf of St. Lawrence. Pond et al. (1971) observed occasional positive values of $\mathrm{Co}_{\mathrm{uw}}$ over the ocean for $f z / U \leq 0.01$ and attributed these to statistical variations. McBean and Miyake (1972) saw positive values of $\mathrm{Co}_{\mathrm{uw}}$ at still higher frequencies in stable conditions over a site that was horizontally homogeneous on a microscale, at least, and inferred that internal waves caused this behavior. Finally, Haugen et al. (1971) reported occasions during the Kansas experiment when the $u w$ product series was positive as a consequence, probably, of horizontal roll vortices (Brown 1980). 


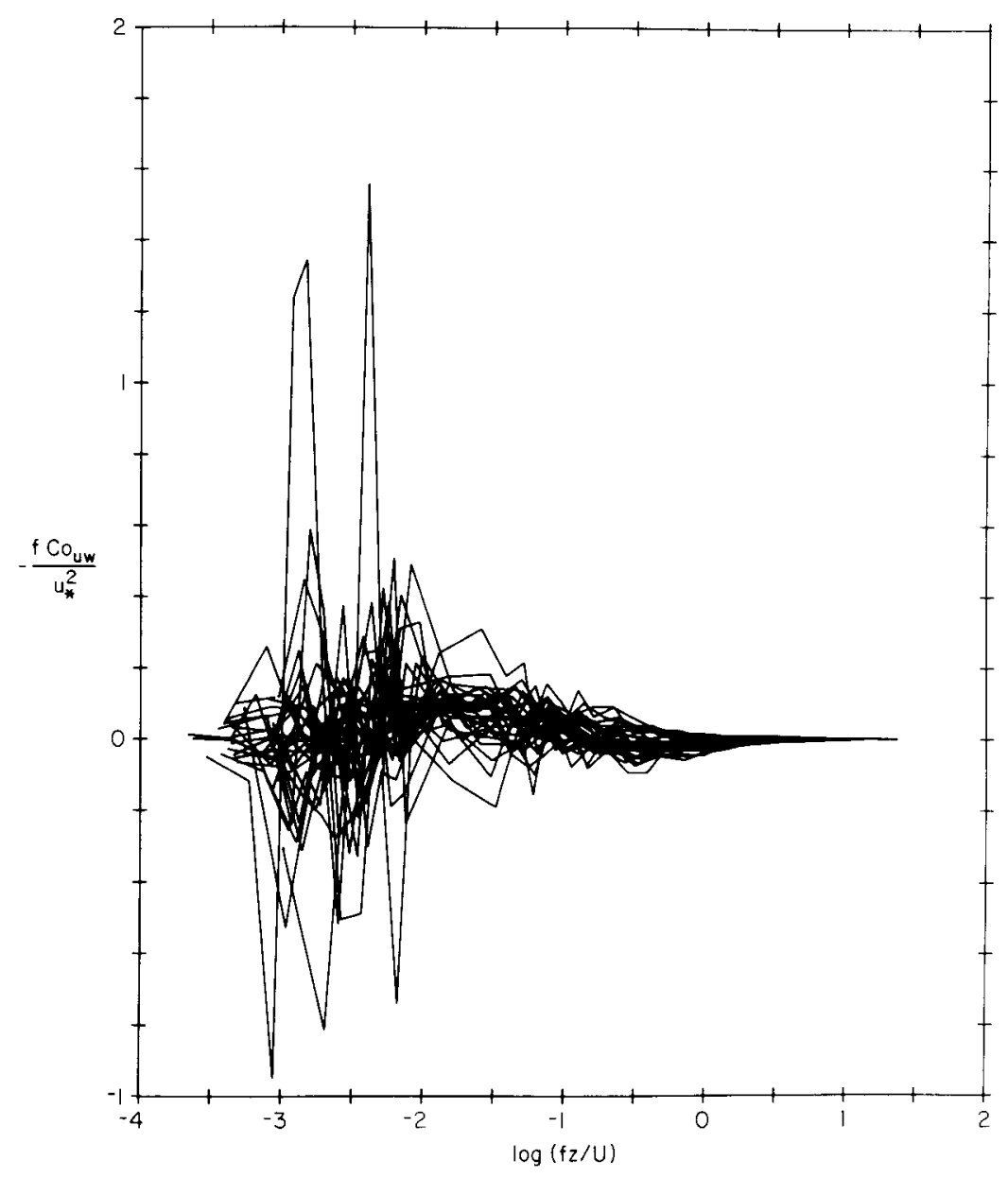

a. u-w cospectra.

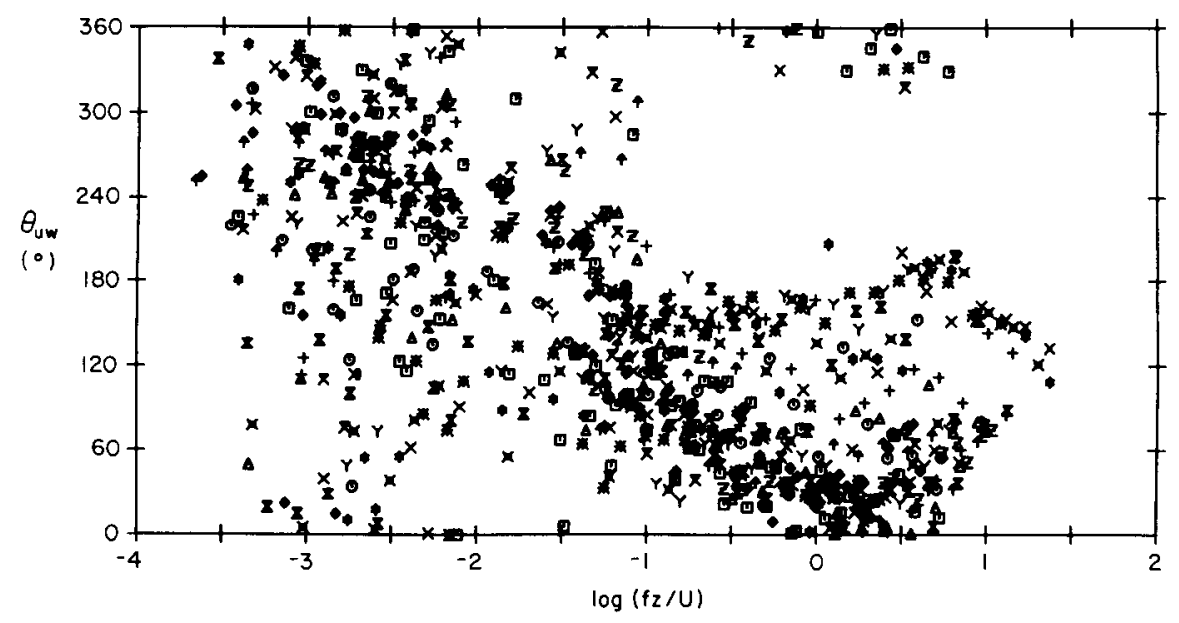

b. Phase spectra.

Figure 7. Plots of the u-w cospectrum, phase spectrum and coherence spectrum for each of the runs in Table 1. 


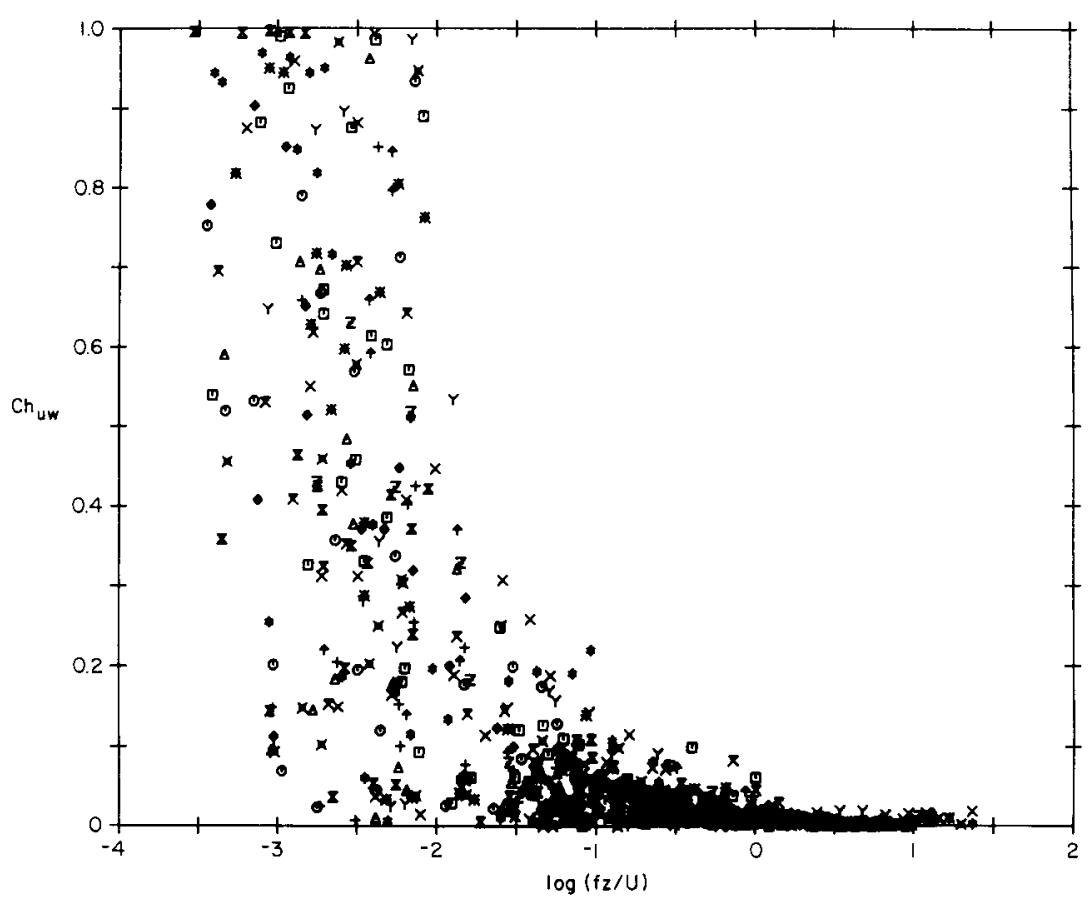

c. Coherence spectra.

Figure 7 (cont'd). Plots of the $\mathrm{u}-\mathrm{w}$ cospectrum, phase spectrum and coherence spectrum for each of the runs in Table 1.

The influence of the topography on the $u-w$ cospectra becomes more obvious when we compare Figures 7 and 8 . Figure 8 a shows six $u-w$ cospectra that are negative throughout the inertial subrange. The runs that produced these cospectra, 2.2, 6.1, 6.2, 6.3, 7.1 and 7.2 (Table 1), all were characterized by winds from the north (Fig. 1) that had not yet crossed any hills. The northerly fetch was also the one with the longest traverse over smooth snow. Although these cospectra have consistent behavior at high frequency, they too have vacillating signs at low frequency, as in Figure $7 \mathrm{a}$. Figures $8 \mathrm{~b}$ and $8 \mathrm{c}$ reiterate the confused cospectral behavior at low frequency, with both phase and coherence spectra generally showing poor correlation between $u$ and $w$. At higher frequency, however, the phase spectra show that the turbulence gets better organized; $\Theta_{u w}$ is roughly $180^{\circ}$, indicating a consistent transfer of momentum to the surface at these scales.

In summary, the topographic effects on the velocity field are dominant at low frequency. Whether the flow is down from the hills or up over them, the topography disrupts the momentum exchange at low frequency, with some scales transferring momentum downward while others transfer it upward. At inertial subrange frequencies the momentum exchange is still confused for downwind measurements within at least $6 h$ of the hills, where $h$ is the height of the hills. For measurements upwind a distance of $6 h$ from the hills, the inertial subrange behaves more normally, with momentum transfer toward the surface at these scales.

\section{$w-t$ and $w-q$ cospectra}

Despite the topographic perturbations the $w-t$ and $w-q$ cospectra (Fig. 9a, 10a, 11a, 12a) have much more consistent behavior throughout their entire frequency range than the $u-w$ cospectra. This difference may indicate that sampling times were too short. Haugen et al. 


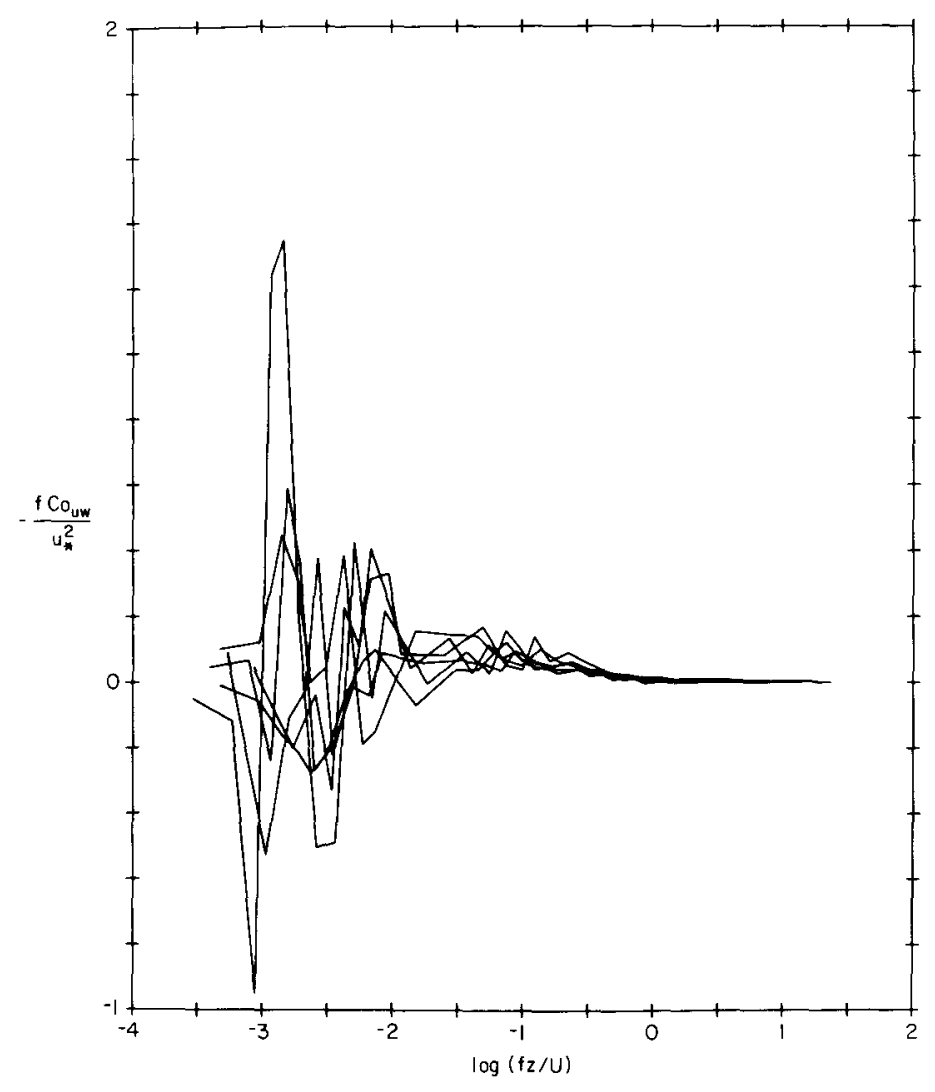

a. u-w cospectra.

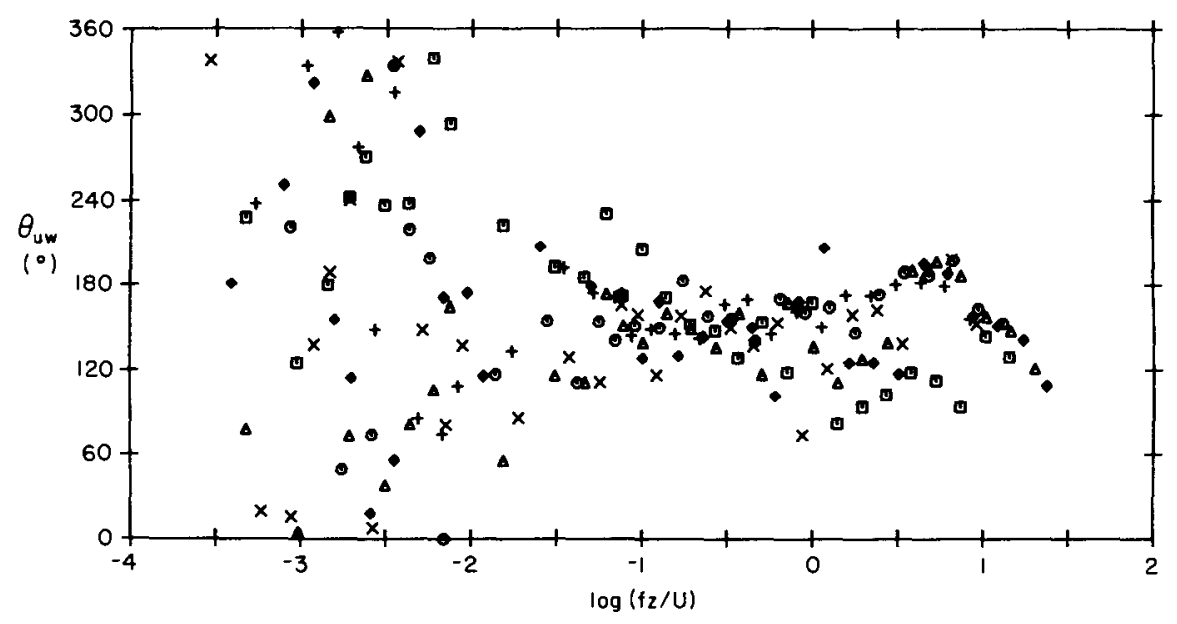

b. Phase spectra.

Figure 8. Plots of u-w cospectra, phase spectra and coherence spectra for the runs in Table 1 in which $\mathrm{Co}_{u w}$ was negative in the inertial subrange. 


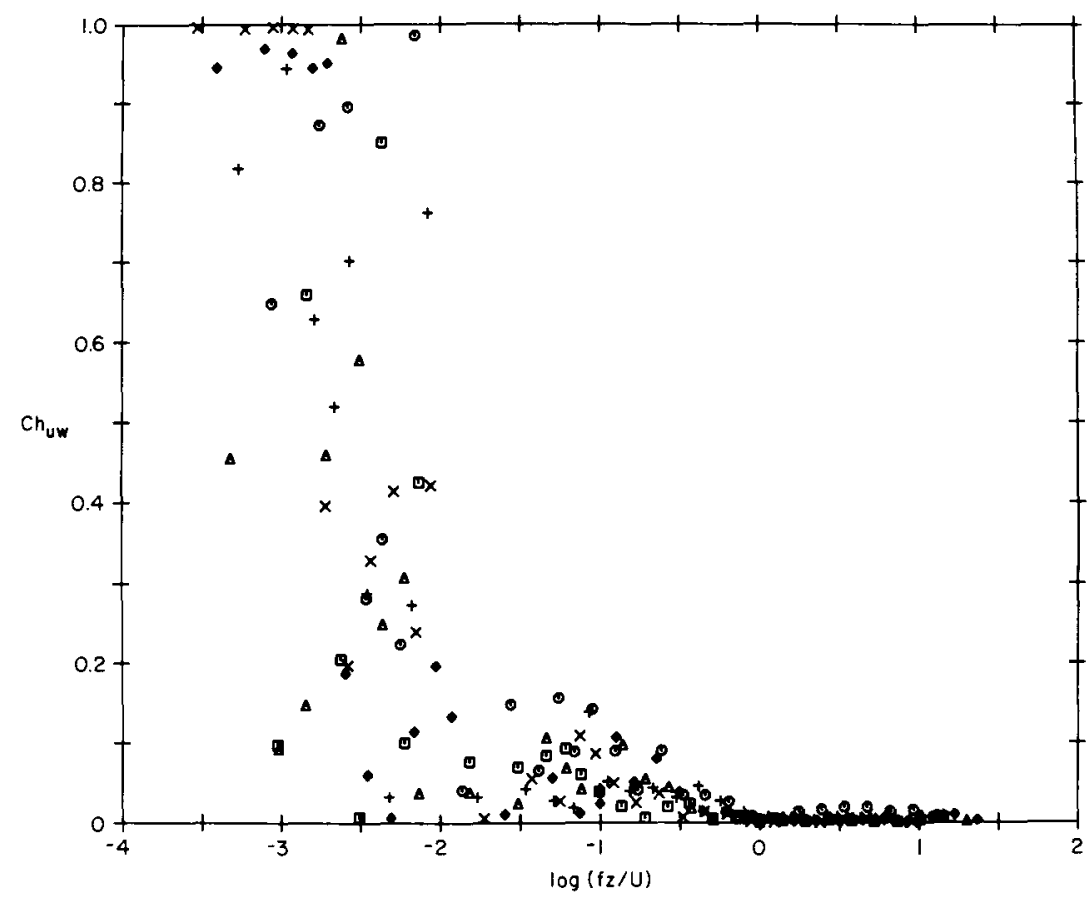

c. Coherence spectra.

Figure 8 (cont'd). Plots of u-w cospectra, phase spectra and coherence spectra for the runs in Table 1 in which $\mathrm{Co}_{u w}$ was negative in the inertial subrange.

(1971) and Wyngaard (1973) recommended sampling times for stress of at least one hour in the surface layer but found shorter times were generally adequate for heat flux. Because of sporadic glitches in my recording system, I seldom had continuous runs longer than 25-30 minutes (Table 1)-about right for sensible and latent heat fluxes but, presumably, too short for stress (Wyngaard 1973).

Figures $9 \mathrm{a}, 10 \mathrm{a}, 11 \mathrm{a}$ and $12 \mathrm{a}$ contain cospectra plotted nondimensionally with typical surface layer scaling (Kaimal et al. 1972). The $u_{*}, t_{*}$ and $q_{*}$ values used in the scaling are from the inertial-dissipation flux estimates. I separated the $w-t$ and $w-q$ spectra into two groups each, depending on whether the cospectra were negative or positive in the inertial-convective subrange. Because Figures 9a, 10a, 11a and 12a plot the spectra logarithmically, they cannot represent spectral estimates with a sign different from that in the inertial-convective subrange; therefore, some points in each cospectrum may have been omitted. The dashed line in each figure is the Kansas neutral-stability $w$ - $t$ cospectrum (Kaimal et al. 1972):

$$
\begin{aligned}
\frac{f C o_{w t}(f)}{u_{*} t} & =11 \frac{f z / U}{[1+13.3(f z / U)]^{1.75}}, \quad f z / U \leq 1.0, \\
& =4.4 \frac{f z / U}{[1+3.8(f z / U)]^{2.4}}, \quad f z / U \geq 1.0 .
\end{aligned}
$$

The majority of $w-t$ cospectra were negative in the inertial-convective subrange (Fig. 9). Despite the uncertainties in the inertial-dissipation technique over complex terrain, the derived $u_{*}$ and $t_{*}$ values collapse the cospectra well at high frequency (Fig. 9a); an inertial- 
convective subrange, where the cospectra go as $f^{-7 / 3}$ (Wyngaard and Cote 1972), is fairly obvious. Although the cospectra collapse well, they consistently fall below eq 26 at its spectral peak and beyond. This suggests that the excess spectral energy at low frequency in the $u$ and $t$ spectra and now in the $w-t$ cospectra was indeed cascading through the inertial subrange, producing higher dissipation rates than would be found in similar conditions over horizontally homogeneous terrain. Consequently the $u_{*} t_{*}$ and $u_{*} q_{*}$ products must be higher (see eq

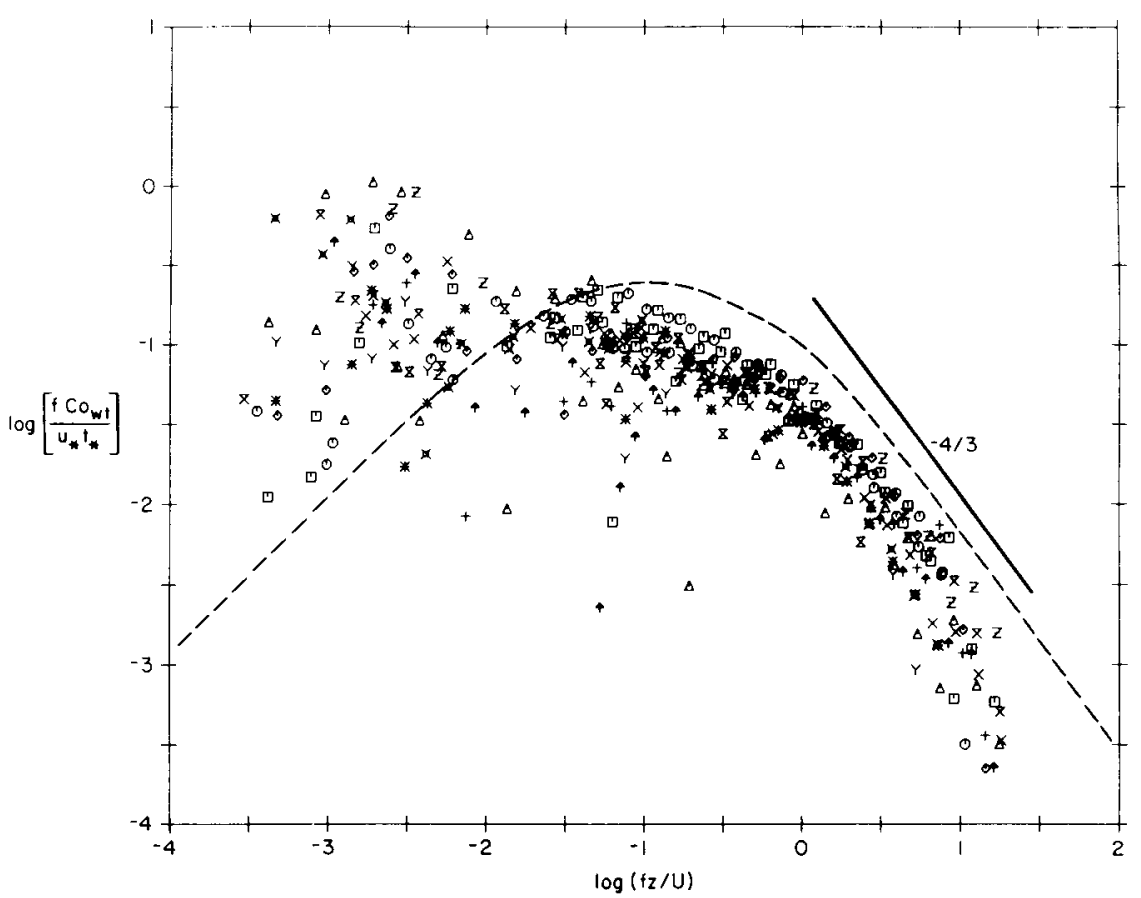

a. $\mathrm{w}-\mathrm{t}$ cospectra.

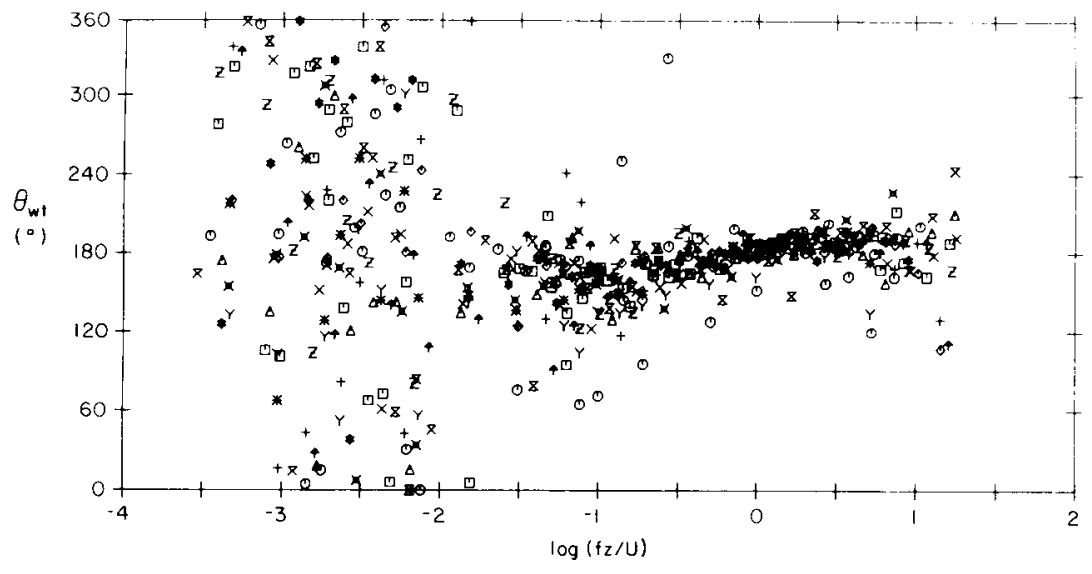

b. Phase spectra.

Figure 9. Plots of $\mathrm{w}-\mathrm{t}$ cospectra, phase spectra and coherence spectra for 16 runs in which $\mathrm{Co}_{w t}$ was predominantly negative in the inertial-convective subrange. The dashed line is the Kansas neutral-stability w-t cospectrum (eq 26). 


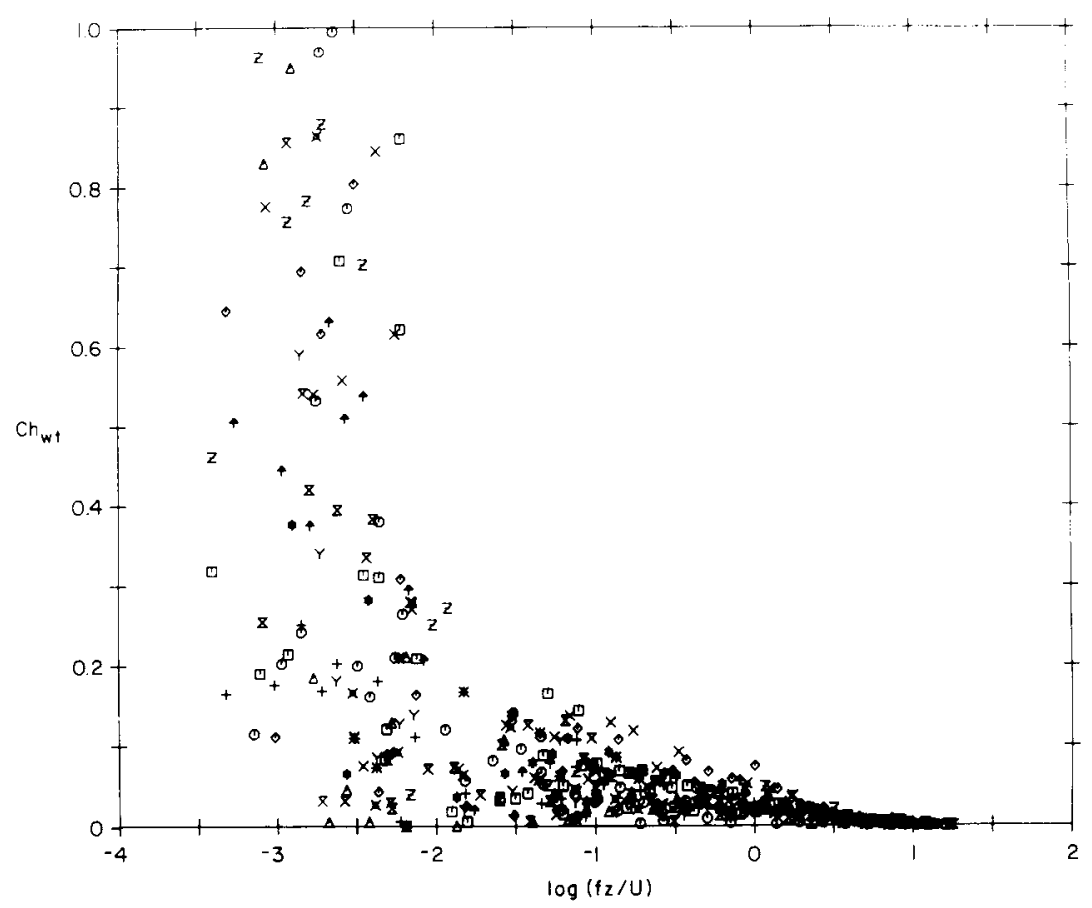

\section{c. Coherence spectra.}

Figure 9 (cont'd). Plots of $\mathrm{w}-\mathrm{t}$ cospectra, phase spectra and coherence spectra for 16 runs in which $\mathrm{Co}_{w t}$ was predominantly negative in the inertial-convective subrange. The dashed line is the Kansas neutral-stability $\mathrm{w}-\mathrm{t}$ cospectrum (eq 26).

10-12). This result is also evident in Figure 9a. Because the integral of $C o_{\mathrm{wt}}$ yields $\overline{w t}=$ $-u_{*} t_{*}$, integrating the measured $w-t$ cospectra-with their excess energy at low frequencywill produce larger $\overline{w t}$ values than integrating the Kansas $w-t$ cospectrum (the dashed line in Fig. 9a).

The phase and coherence spectra (Fig. 9b and c) emphasize the more consistent behavior of the $w-t$ cospectra. For nondimensional frequencies above 0.1 , the phase spectra cluster around $180^{\circ}$, indicating that the $w$ and $t$ fluctuations had good negative correlation. At lower frequencies the phase spectra are more scattered, but the bulk of the points are between $90^{\circ}$ and $270^{\circ}$. That is, the correlation generally remains negative at low frequency; the spectral estimates outside this range indicate that some cospectral estimates have gone positive. Compare the $u-w$ phase spectra (Fig. 7b). At high frequency, $\Theta_{\mathrm{uw}}$ is typically between $0^{\circ}$ and $90^{\circ}\left(\mathrm{Co}_{\mathrm{uw}}\right.$ positive), while at low frequency the majority of the spectral estimates are in the $180-270^{\circ}$ quadrant ( $\mathrm{Co}_{\mathrm{uw}}$ negative). The $w-t$ coherence spectra (Fig. 9c) show moderate correlation at low frequency. With the high energy levels in the $w$ and $t$ spectra here, this results in the high cospectral energy evident in Figure 9a.

The $w-t$ cospectra that are predominantly positive in the inertial-convective subrange are more erratic (Fig. 10). The collapse of the cospectra when scaled with $u_{*} t$ is not very successful, even at high frequency (Fig. 10a). The phase spectra (Fig. 10b) show that the sign usually changes between low (negative) and high (positive) frequencies. The coherence spectra (Fig. $10 \mathrm{c})$ are not dramatically different from those in Figure $9 \mathrm{c}$ except in the extended portion of the spectrum, where a higher percentage of spectral estimates have $C h_{\mathrm{wt}}$ values much larger than 1 (and, hence, off the plot) than for the negative cospectra. The probable cause of this 
erratic behavior is the low energy in the positive $w$ - $t$ cospectra. Table 2 shows that the runs with $\mathrm{Co}_{\mathrm{wt}}$ positive in the inertial-convective subrange (positive $H_{\mathrm{s}}$ ) had some of the smallest absolute values of $H_{\mathrm{s}}$.

An overwhelming majority of the $w-q$ cospectra are positive in the inertial-convective subrange (Fig. 11a). Again the surface-layer nondimensionalization collapses these cospectra well at peak frequencies and beyond. An inertial-convective subrange, where $\mathrm{Co}_{\mathrm{wq}}$ goes as $f^{-7 / 3}$, is evident. But, as with the $w-t$ cospectra, at high frequency the nondimensional cospectra fall below the neutral-stability Kansas $w$ - $t$ cospectrum (eq 26). I attribute this again to higher values of $u_{*} q_{*}$ at this topographically complex site than would derive over horizontally homogeneous terrain. At low frequency the $w-q$ cospectral estimates are not as consistently above the Kansas cospectrum as were the $w-t$ cospectral estimates in Figure 9a. This could be a consequence of poorer coherence between the $w$ and $q$ fluctuations (Fig. 11c) or, more probably, the slightly lower energy in $\Phi_{q}$ than in $\Phi_{t}$ at low frequency.

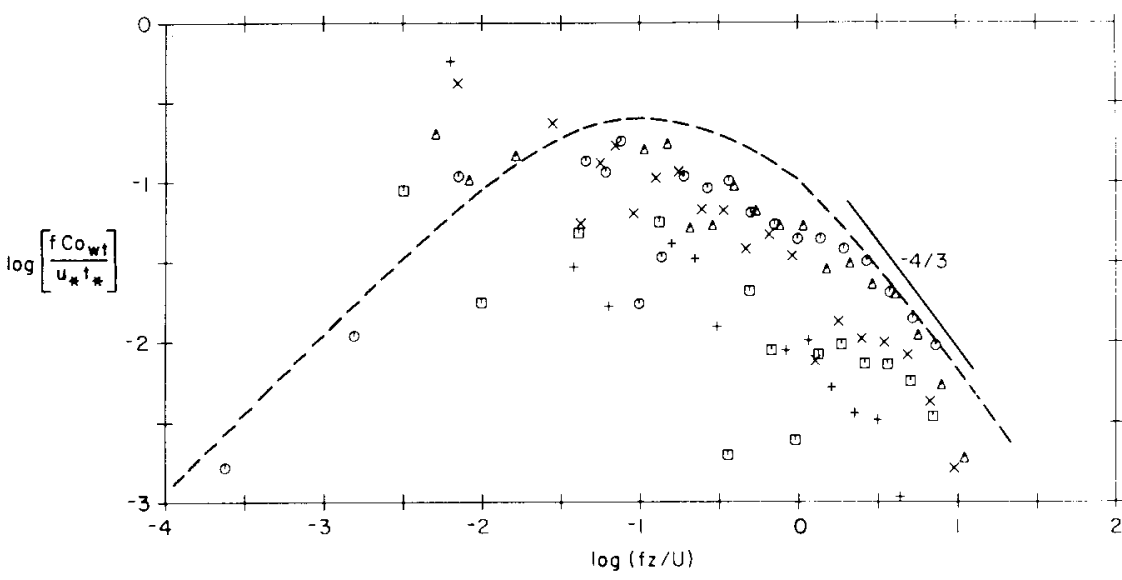

a. w-t cospectra.

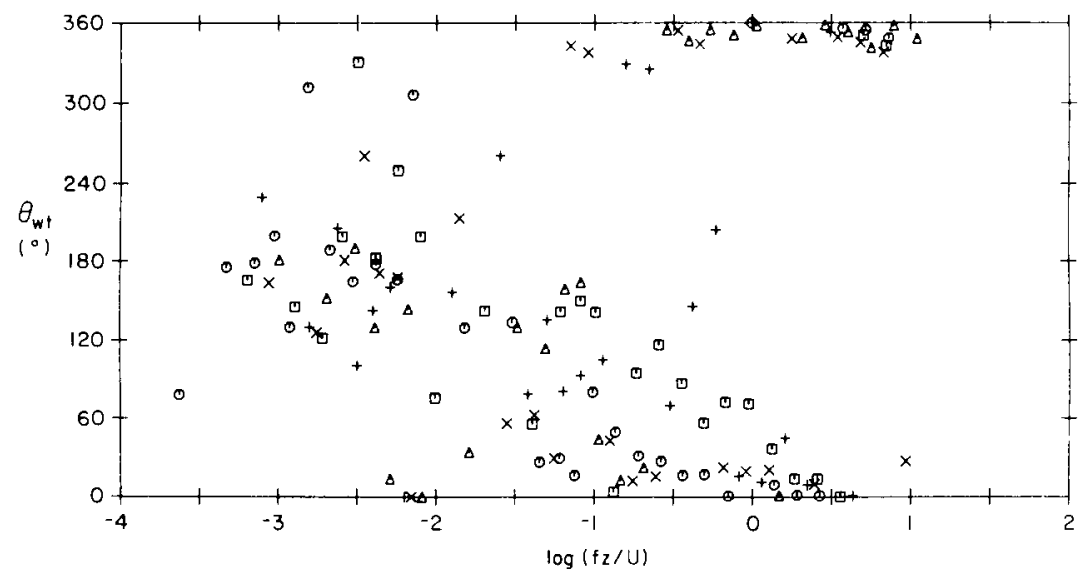

\section{b. Phase spectra.}

Figure 10. Plots of $\mathrm{w}-\mathrm{t}$ cospectra, phase spectra and coherence spectra for five runs in which $\mathrm{Co}_{w t}$ was positive in the inertial-convective subrange. The dashed line is the Kansas neutral-stability $\mathrm{w}-\mathrm{t}$ cospectrum (eq 26). 


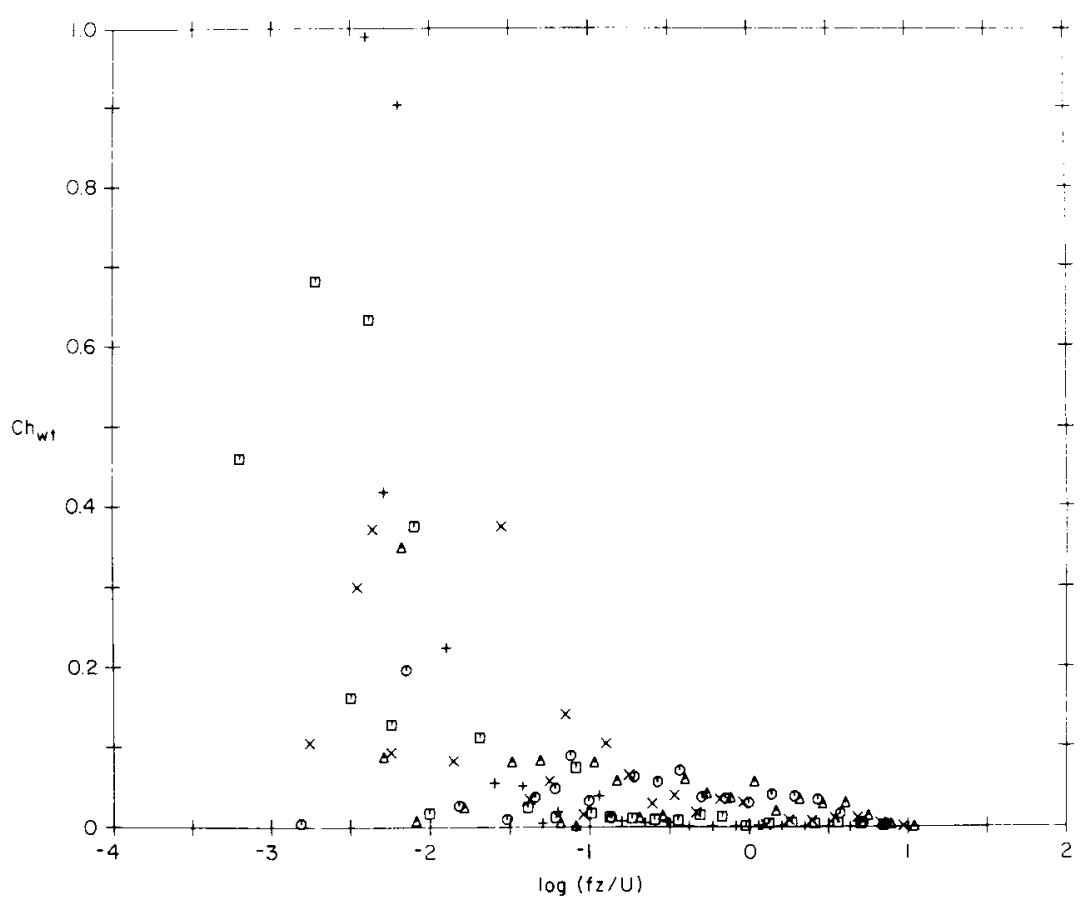

c. Coherence spectra.

Figure 10 (cont'd). Plots of $\mathrm{w}-\mathrm{t}$ cospectra, phase spectra and coherence spectra for five runs in which $\mathrm{Co}_{w t}$ was positive in the inertial-convective subrange. The dashed line is the Kansas neutral-stability w-t cospectrum (eq 26).

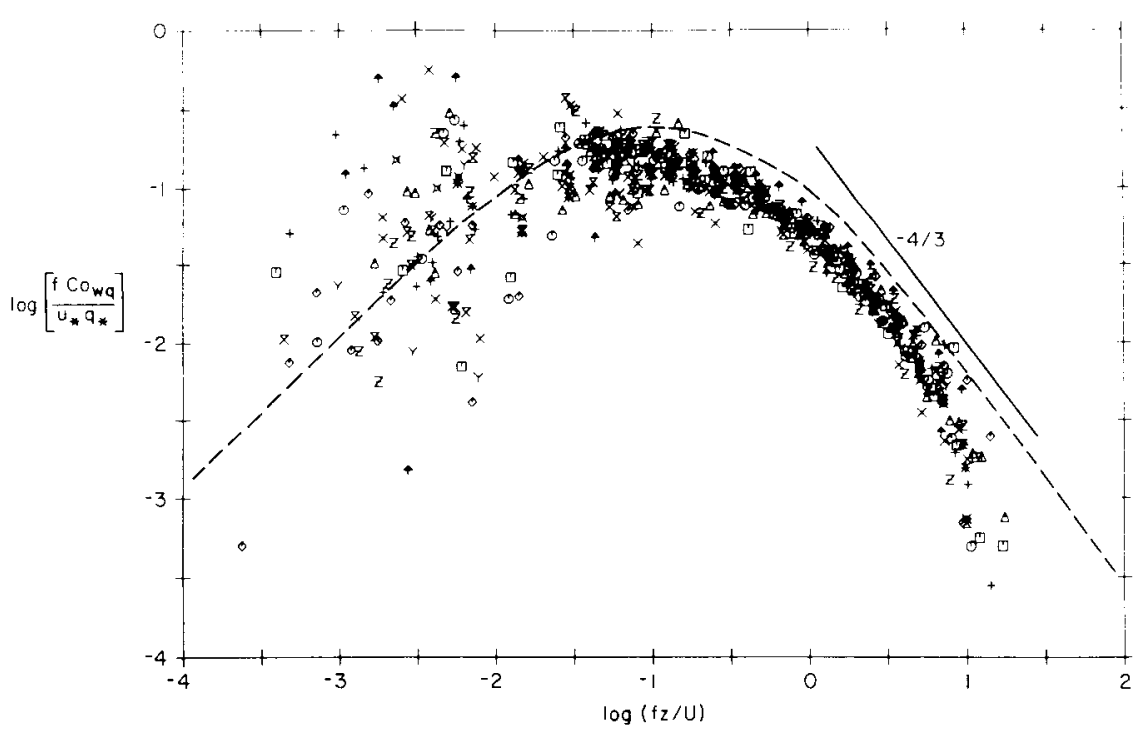

a. $\mathrm{w}-\mathrm{q}$ cospectra.

Figure 11. Plots of $\mathrm{w}-\mathrm{q}$ cospectra, phase spectra and coherence spectra for 22 runs in which $\mathrm{Co}_{w q}$ was positive in the inertial-convective subrange. The dashed line is the Kansas neutral-stability w-t cospectrum (eq 26). 


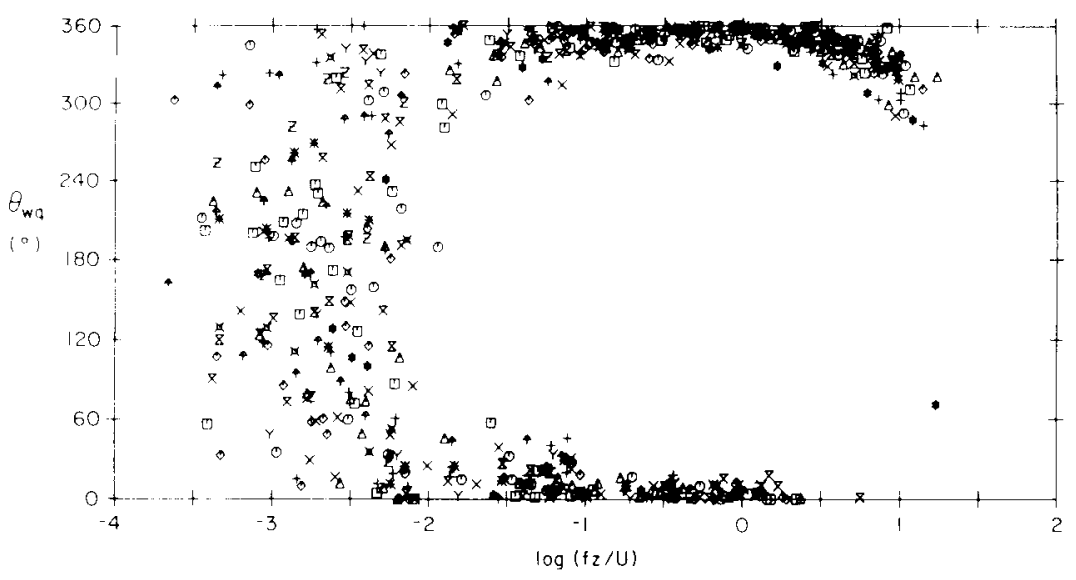

b. Phase spectra.

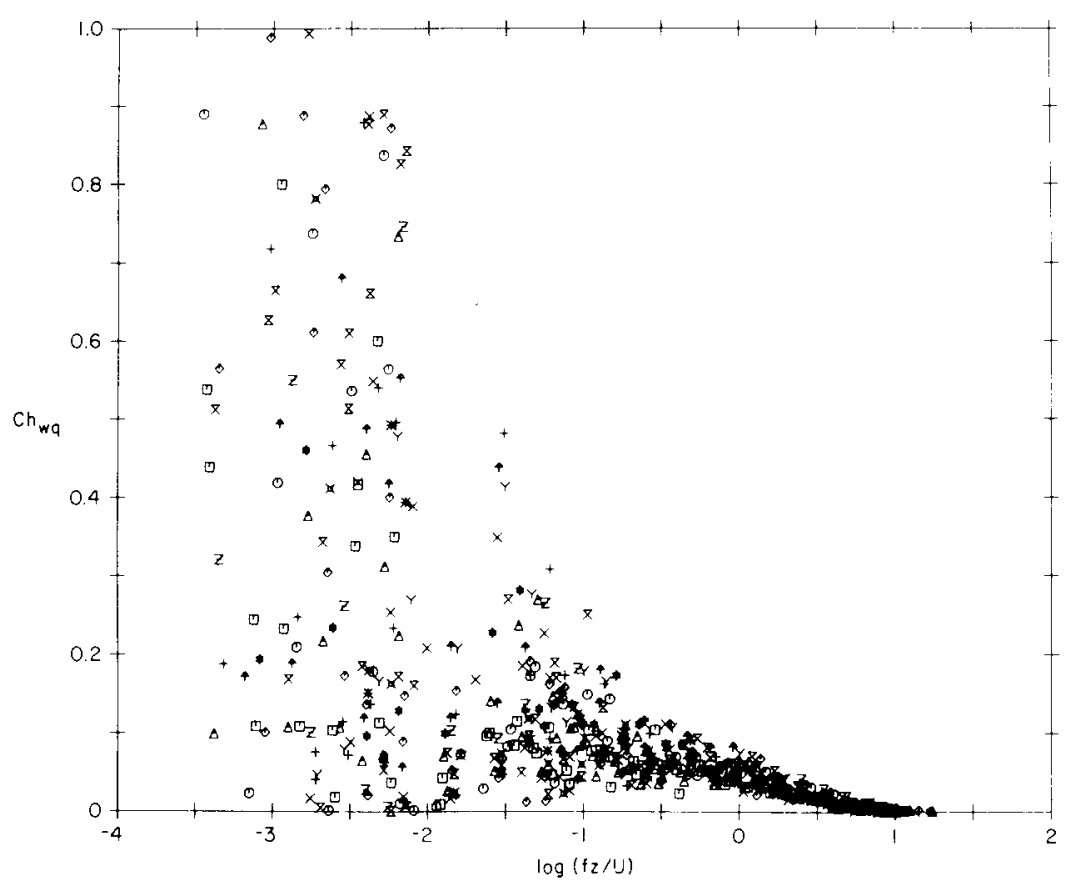

c. Coherence spectra.

Figure 11 (cont'd).

The cospectrum and phase and coherence spectra for the one run (11.2) for which $\mathrm{Co}_{\mathrm{wq}}$ was negative in the inertial-convective subrange are shown in Figure 12. Again $\mathrm{Co}_{\mathrm{wq}}$ falls below the Kansas $w-t$ cospectrum at its peak and beyond. The phase spectrum indicates consistent negative correlation at high frequency but sign reversals at low frequency.

The vacillating sign at low frequency and the frequent sign difference between low and high frequencies in the $w-t$ and $w-q$ cospectra suggest little coherence between transfer processes at large and small scales at our site. The small scales seem to be near equilibrium with the snow surface because inertial-dissipation estimates-based on the high-frequency behavior of $\Phi_{\mathrm{u}}, \Phi_{\mathrm{t}}$ and $\Phi_{\mathrm{q}}$ and on the signs of $C o_{\mathrm{wt}}$ and $C o_{\mathrm{wq}}$ in the inertial-convective subrange- 
yield reasonable values of $H_{\mathrm{s}}$ and $H_{\mathrm{L}}$ and values of $u_{*}, t_{*}$ and $q_{*}$ that are effective in collapsing $\mathrm{Co}_{\mathrm{wt}}$ and $\mathrm{Co}_{\mathrm{wq}}$ to consistent form. These $H_{\mathrm{s}}$ values are also consistent with upper-air soundings made during the experiment. Although soundings were not always made twice a day during the experiment, the available soundings consistently showed a shallow inversion layer, with a well-mixed layer above. Therefore, the predominantly negative $H_{\mathrm{s}}$ values that the inertial-dissipation technique yielded (Table 2) are consistent with atmospheric boundary layer profiles.

\section{$t-q$ cospectra}

Because the $w-t$ cospectra were generally negative in the inertial-convective subrange while the $w-q$ cospectra were virtually always positive, the temperature and humidity fluctuations were of ten negatively correlated. The $t-q$ cospectra reiterate this conclusion and point out other interesting aspects of temperature and humidity transfer over complex terrain.

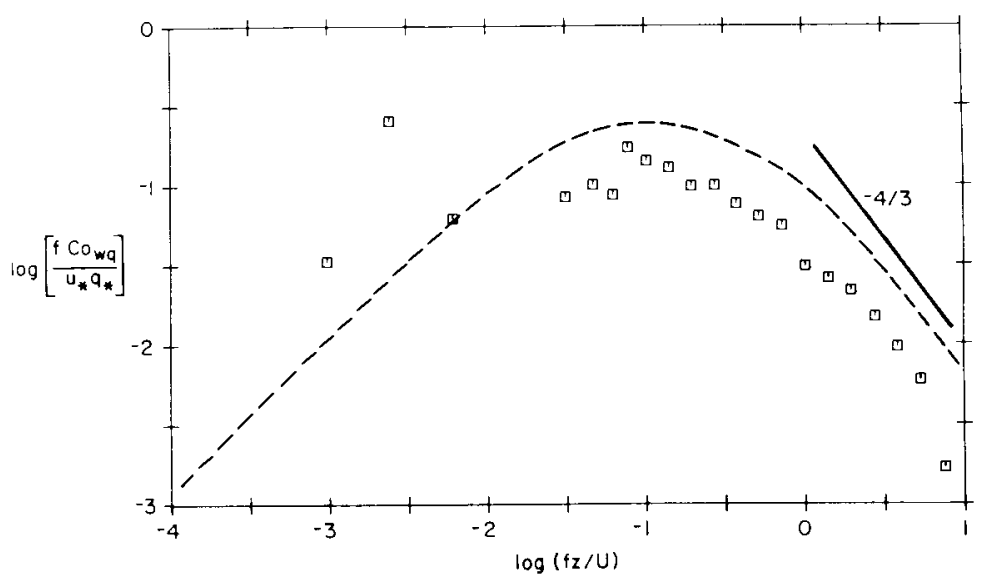

a. $\mathrm{w}-\mathrm{q}$ cospectrum.

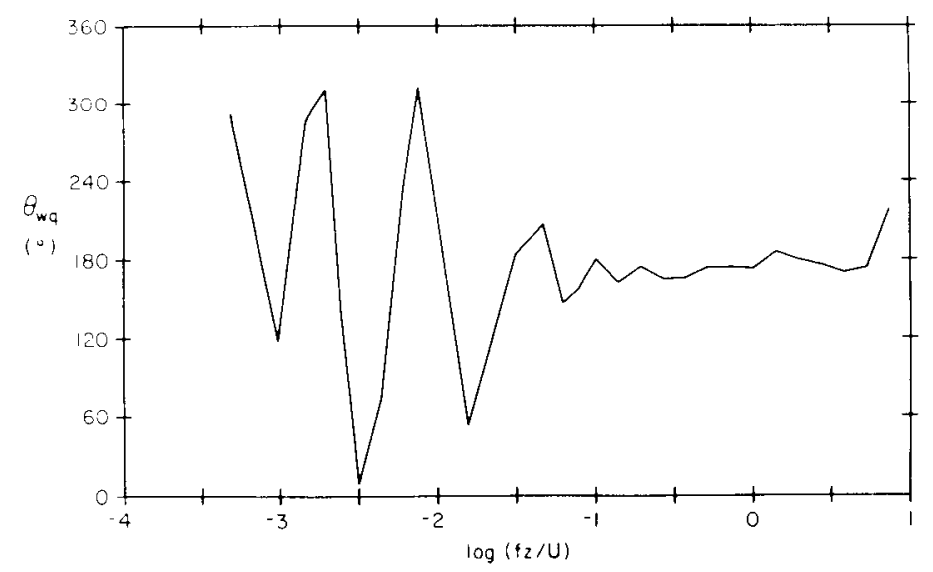

b. Phase spectrum.

Figure 12. Plots of the $\mathrm{w}-\mathrm{q}$ cospectrum, phase spectrum and coherence spectrum for the one run (11.2) in which $\mathrm{Co}_{w q}$ was negative in the inertial-convective subrange. The dashed line is the Kansas neutral-stability $\mathrm{w}-\mathrm{t}$ cospectrum (eq 26). 


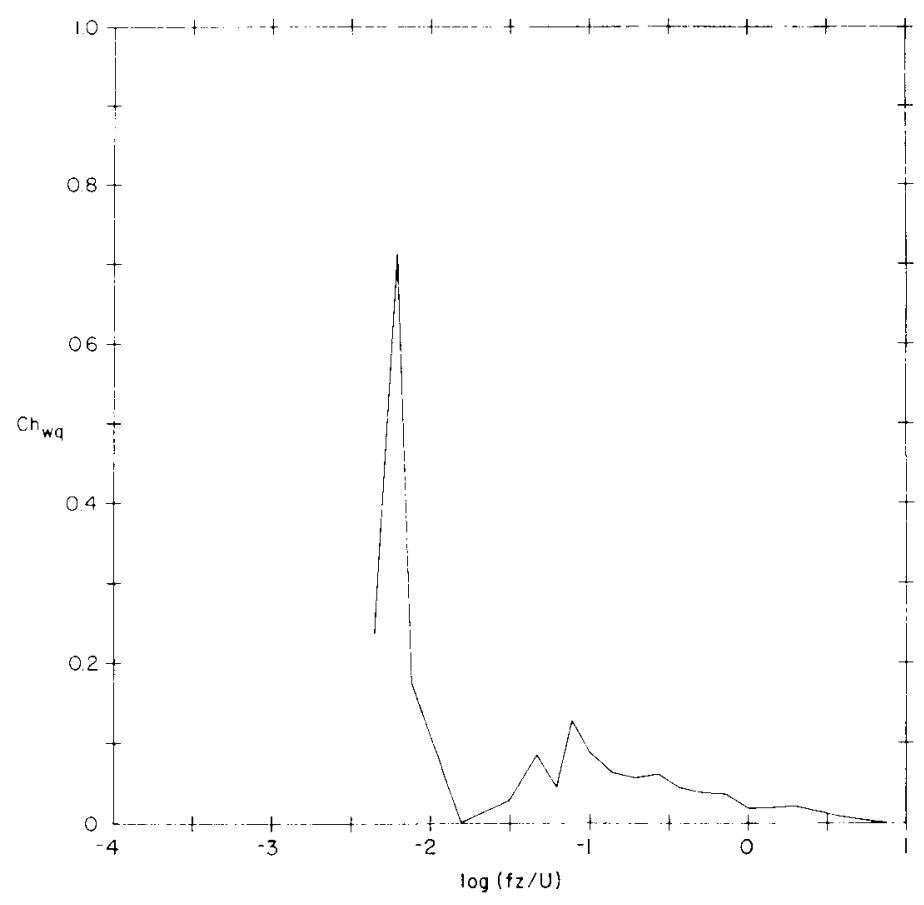

c. Coherence spectrum.

Figure 12 (cont'd).

As with the $w-t$ and $w-q$ cospectra, I have grouped the $t-q$ cospectra according to whether they are negative or positive in the inertial-convective subrange. Figure 13 shows cospectra and phase and coherence spectra for $t-q$ cospectra that are negative in the inertial-convective subrange; Figure 14 shows the same plots for $t-q$ cospectra that are positive. The nondimensionalization in Figures 13a and 14a again reflects surface-layer scaling based on the prediction that $\mathrm{Co}_{\mathrm{tq}}$ should behave in an inertial-convective subrange just like temperature and humidity spectra (Friehe et al. 1975, Wyngaard et al. 1978):

$$
C o_{\mathrm{tq}}(k)=\beta_{\mathrm{tq}} N_{\mathrm{tq}} \epsilon^{-1 / 3} k^{-5 / 3}
$$

Here $N_{\mathrm{tq}}$ is the dissipation rate of the $t-q$ covariance; and I assume $\beta_{\mathrm{tq}}=0.40$, half the value used for the temperature and humidity spectra (Antonia et al. 1978, Hill 1978). Since $C o_{\mathrm{tq}}$ is assumed to behave like temperature and humidity spectra, the dashed line in Figures 13a and 14a is the Kansas neutral-stability temperature spectrum (eq 6).

The surface-layer nondimensionalization works well for both negative and positive $t-q$ cospectra. The cospectra, especially the negative $t-q$ cospectra, collapse well in the inertialconvective subrange (Fig. 13a and 14a). Both sets of cospectra, however, generally have more energy than the Kansas temperature spectrum for frequencies at its peak and lower. Because of this excess energy at low frequency, the $t-q$ cospectra have $f^{-5 / 3}$ regions that begin at a frequency roughly an order of magnitude lower than in the Kansas spectrum. Remember, we observed these same features in the temperature and humidity spectra. Thus, although my scalar spectra and cospectra do not look exactly like the Kansas temperature spectrum, they look very much like each other. 


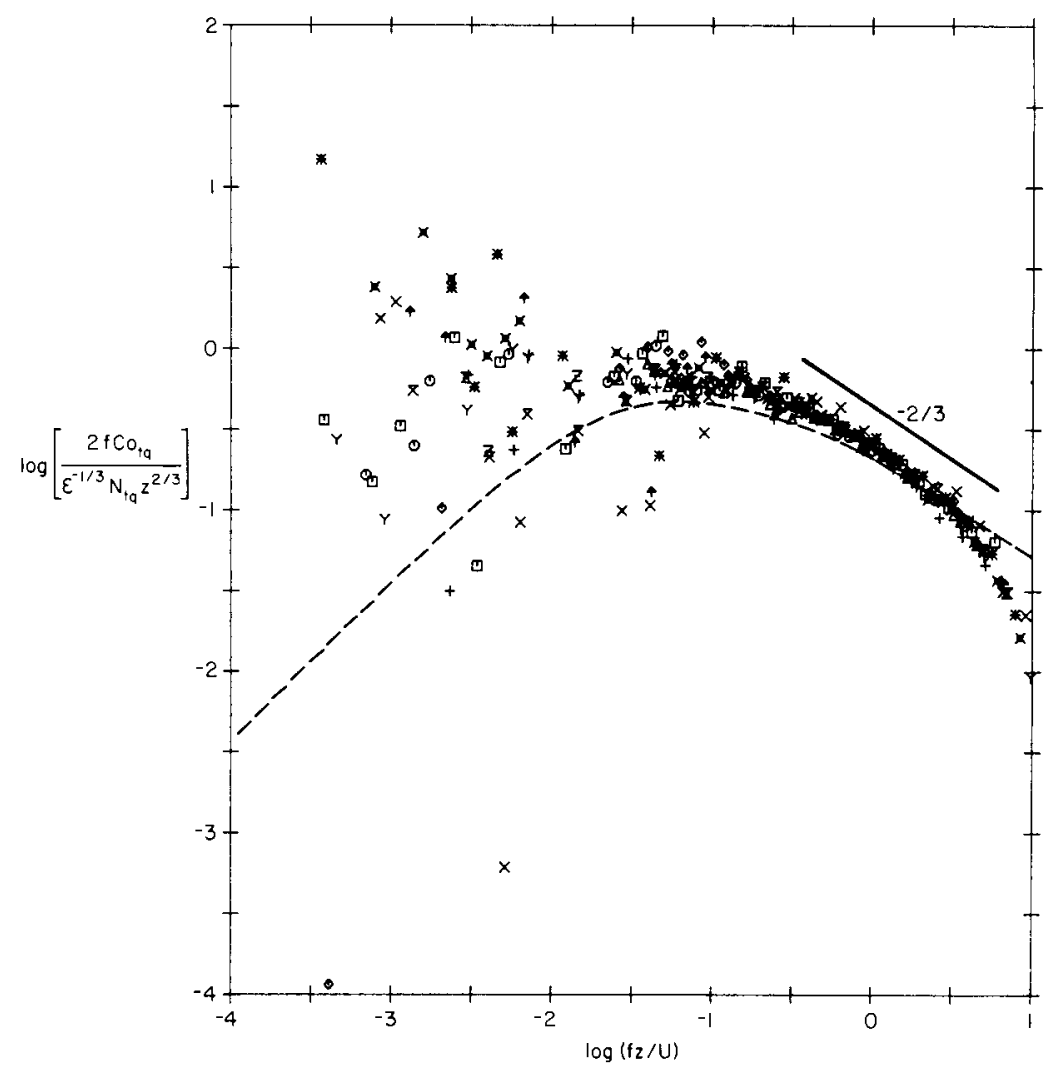

a. $\mathrm{t}-\mathrm{q}$ cospectra.

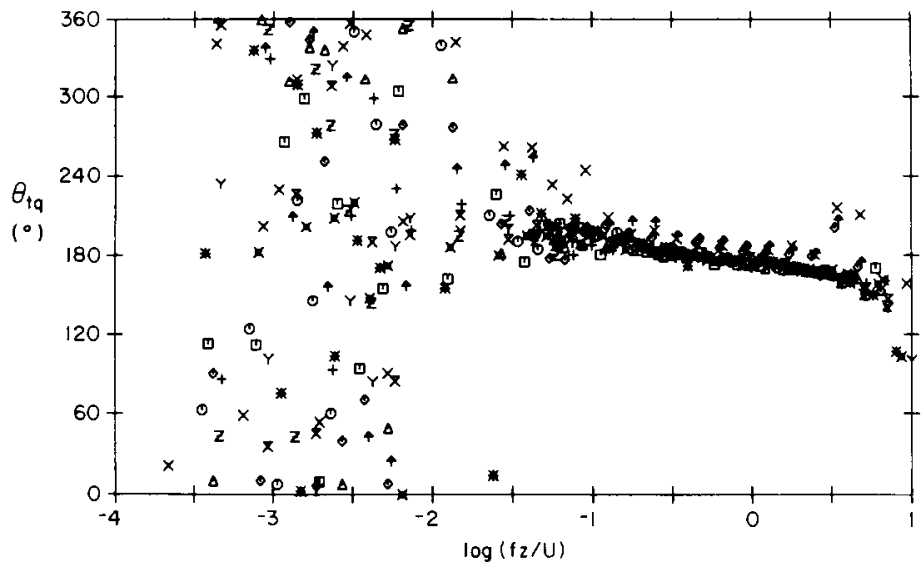

b. Phase spectra.

Figure 13. Plots of $\mathrm{t}-\mathrm{q}$ cospectra, phase spectra and coherence spectra for 12 runs in which $\mathrm{Co}_{t q}$ was predominantly negative in the inertial-convective subrange. The dashed line is the Kansas neutralstability temperature spectrum (eq 6). 


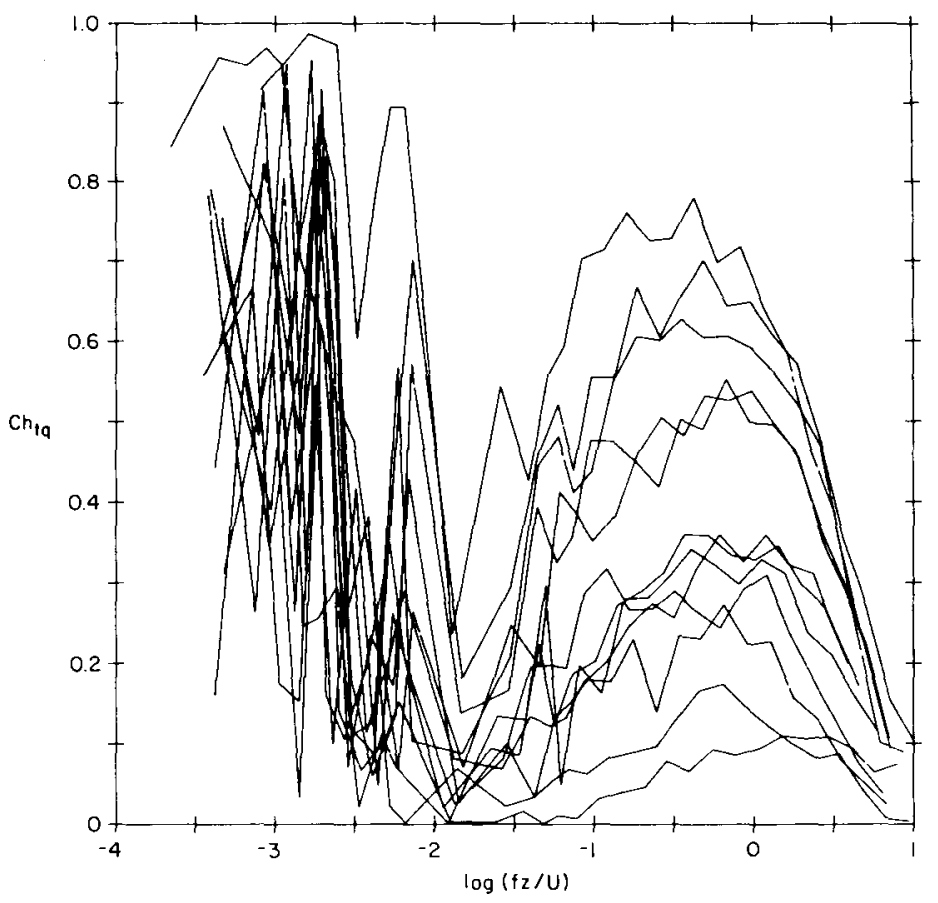

c. Coherence spectra.

Figure 13 (cont'd).

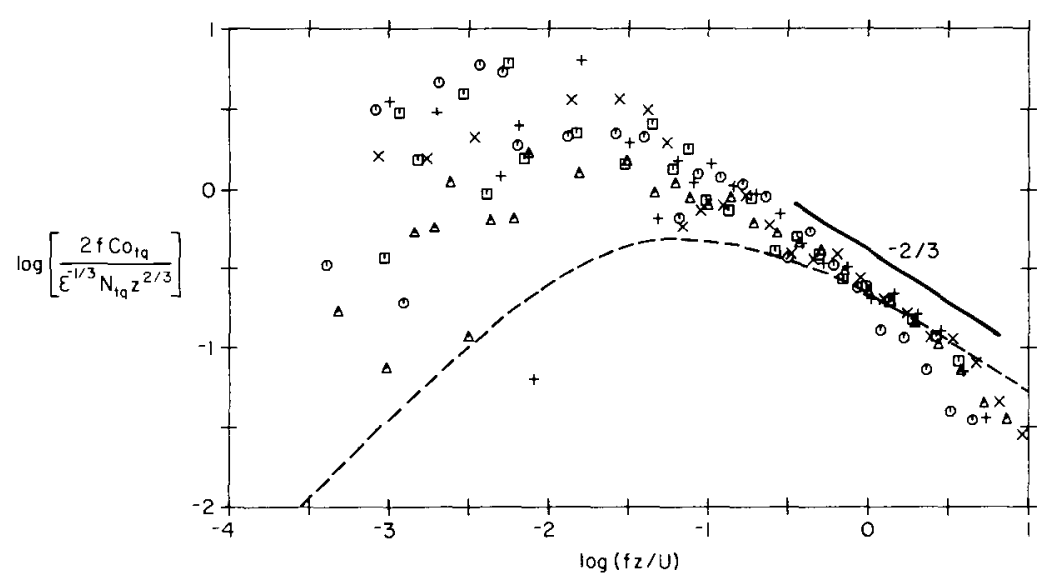

a. $\mathrm{t}-\mathrm{q}$ cospectra.

Figure 14. Plots of $\mathrm{t}-\mathrm{q}$ cospectra, phase spectra and coherence spectra for five runs in which $\mathrm{Co}_{t q}$ was positive in the inertial-convective subrange. The dashed line is the Kansas neutral-stability temperature spectrum (eq 6). 


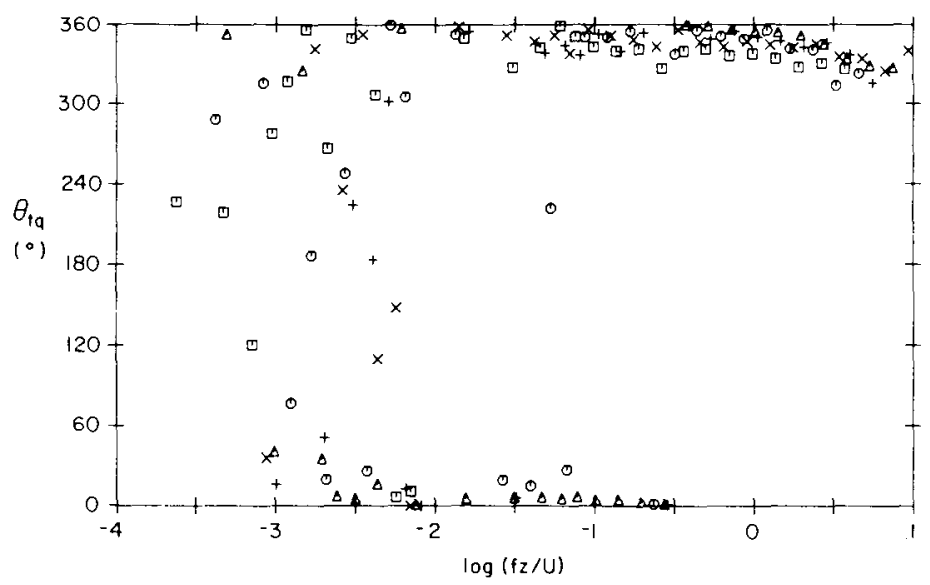

b. Phase spectra.

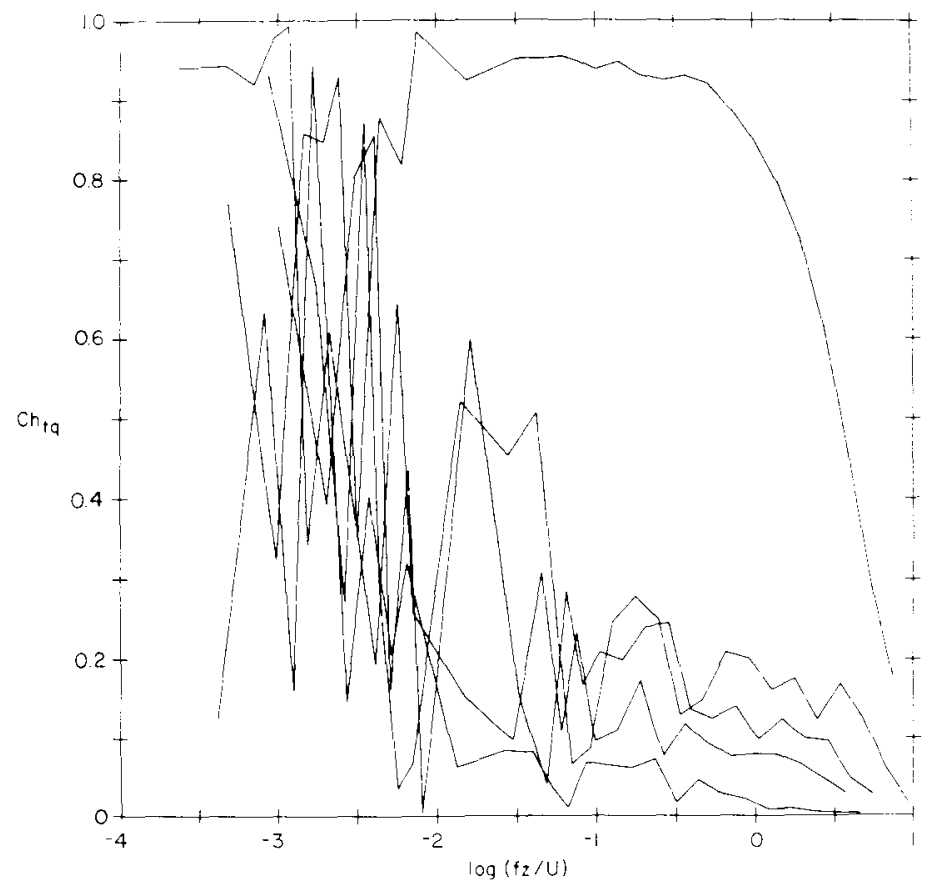

c. Coherence spectra.

Figure 14 (cont'd). Plots of $\mathrm{t}-\mathrm{q}$ cospectra, phase spectra and coherence spectra for five runs in which $\mathrm{Co}_{t q}$ was positive in the inertial-convective subrange. The dashed line is the Kansas neutral-stability temperature spectrum (eq 6).

The one anomalous feature of the $t-q$ cospectra is that the inertial-convective subrange, the $f^{-5 / 3}$ region, does not extend to frequencies as high as it does in the $t$ and $q$ spectra, although it theoretically should. The reason is the separation between the $t$ and $q$ sensors, $d=$ $4 \mathrm{~cm}$. Kaimal (1975) explained that as the turbulence frequency gets higher and the eddy size becomes comparable to the separation between sensors, the turbulence at the two sensors becomes increasingly uncorrelated. The nondimensional frequency $f z / U$ at which this occurs is 
roughly $z / 6 \pi d$. For my measurements this value is about 3 [or $\log (z / 6 \pi d)$ ], which corresponds well with the frequency in Figures 13a and 14a, where the cospectra turn down from the $-2 / 3$ slope. The phase spectra (Fig. 13b and 14b) also start losing their inertial-subrange consistency near this frequency (Priestley and Hill 1985). Recognizing this effect in the $t-q$ cospectra, we can also go back and see it in the more scattered $w-t$ and $w-q$ cospectra. The hot-film sensors that yielded $w$ were $4 \mathrm{~cm}$ from the Lyman-alpha hygrometer and $2.5 \mathrm{~cm}$ from the PRT. Hence, the change in slope for $\mathrm{Co}_{\mathrm{wt}}$ and $\mathrm{Co}_{\mathrm{wq}}$ in Figures 9a and 11a occurs at roughly the same frequency as for $\mathrm{Co}_{\mathrm{tq}}$.

Because few measurements of $t-q$ cospectra have been reported, the validity of the inertialconvective subrange form of the cospectrum (eq 27) is still tentative. Friehe et al. (1975) presented one negative cospectrum obtained over the Salton Sea and one, likely positive, cospectrum measured over the ocean. Both had the predicted inertial-convective subrange behavior. Wyngaard et al. (1978) showed one positive $t-q$ cospectrum that behaved as $f^{-5 / 3}$ in the inertial-convective subrange and said it was typical of the 40 cospectra that they had obtained over the East China Sea. They also stated that unpublished $t-q$ cospectra computed from data collected by Champagne et al. (1977) over Minnesota farmland also showed inertial-convective subranges. These were likely also positive cospectra. Antonia and Chambers (1980) also showed one positive cospectrum that went as $f^{-5 / 3}$ at high frequency and was representative of the four they had measured over Bass Strait. Priestley and Hill (1985) measured six positive and six negative $t-q$ cospectra at BAO that behaved as $f^{-5 / 3}$. McBean and Elliott (1981) and Kohsiek (1982), however, did not find the predicted inertial-convective subrange behavior in the $t-q$ cospectra that they obtained over dry land. Figure $13 \mathrm{a}$ is thus important confirmation of the existence of an $f^{-5 / 3}$ inertial-convective subrange in negative $t-q$ cospectra.

As with essentially all the cospectra that I have presented, the $t-q$ cospectra tend to have different signs at low and high frequencies. The phase spectra (Fig. 13b and 14b) show this clearly. For the runs with $\mathrm{Co}_{\mathrm{tq}}$ positive in the inertial-convective subrange, this tendency is not as pronounced as when $C o_{\mathrm{tq}}$ is negative. Nevertheless the phase spectra suggest that the scalar content of large and small eddies was often different. For example, for $\mathrm{Co}_{\mathrm{tq}}$ negative in the inertial-convective subrange (Fig. 13), at high frequency warm eddies were generally drier than ambient conditions, while cool eddies were more moist. At low frequency, on the other hand, warm eddies were often more moist than ambient conditions, while cool eddies were drier.

The $t-q$ coherence spectra (Fig. $13 \mathrm{c}$ and $14 \mathrm{c}$ ) are different from any of the other coherence spectra. First, the coherence is higher at high frequency than for $u-w, w-t$ or $w-q$. This is a consequence not only of the better correlation (both positive and negative) between temperature and humidity fluctuations at high frequency but also of the less-rapid roll-off of $C o_{\mathrm{tq}}$ than of $\mathrm{Co}_{\mathrm{uw}}, \mathrm{Co}_{\mathrm{wt}}$ and $\mathrm{Co}_{\mathrm{wq}}$ (Fairall et al. 1980). The one run that had $C h_{\mathrm{tq}}$ values conspicuously above 0.90 in Figure $14 \mathrm{c}$ was 11.2 -the only run during which $H_{\mathrm{s}}$ and $H_{\mathrm{L}}$ were both negative (Table 2). This seems to suggest that $t$ and $q$ have a better positive correlation at high frequency in stable conditions than in unstable conditions. Although few corroborating coherence spectra have been reported, Priestley and Hill (1985) did point out that in their data-for which $H_{\mathrm{L}}$ was always positive-the $t-q$ coherence was usually higher in stable than in unstable conditions.

A second important feature of the coherence spectra is the dichotomy indicated in Figure 13c. The coherence spectra are generally high at low frequency, have local minima near $f z / U$ $=0.02$, then peak again in the inertial-convective subrange. The conclusion must again be that large-scale and small-scale transport processes are dissimilar. The phase spectra in Figure $13 \mathrm{~b}$ corroborate this conclusion; they are consistently near $180^{\circ}$ above $f z / U=0.02$ and scattered at lower frequencies. The runs that yielded Figure 13 were all characterized by 
stable conditions. In stable conditions, McBean and Miyake (1972) saw $w-t$ coherence spectra similar to these $t-q$ coherence spectra and attributed their shape to internal gravity waves. If only internal waves were responsible for the mixing, however, the phase spectra in Figure $13 \mathrm{~b}$ would also be near $180^{\circ}$ at low frequency (positive temperature gradient, negative humidity gradient), which they are not. Hence, McBean and Miyake (1972) hypothesized that the fluctuations at high frequency were caused strictly by turbulence; but at low frequency they resulted from a combination of turbulence and internal gravity waves. Caughey (1977) reached basically the same conclusion: Because the frequency ranges of the turbulence and the internal waves overlap, phase and coherence spectra will not show characteristic wave signatures.

Finding this suggestion of internal waves in the $t$ - $q$ phase and coherence spectra, we can look for additional evidence of waves in the spectra and cospectra we have already discussed. The $w-t$ coherence and phase spectra for negative $C o_{\mathrm{wt}}$ (stable conditions), for example, behave like these $t-q$ phase and coherence spectra. The coherence spectra have local minima at about $f z / U=0.02$, and the phase spectra are near $180^{\circ}$ at frequencies above this but are erratic below. The $w-t$ cospectra in Figure $9 \mathrm{a}$ and the $t-q$ cospectra in Figure 13a both have local minima near $f z / U=0.02$, too. Caughey (1977) took this local minimum, or "spectral gap," as he called it, to be a signal that internal waves were present at frequencies below the gap.

\section{REFRACTIVE INDEX SPECTRA}

With simultaneous measurements of the turbulent fluctuations in temperature and humidity, it is possible to compute the fluctuations in refractive index $n$ for arbitrary electromagnetic wavelength $\lambda$ from

$$
n=A(\lambda, P, T, Q) t+B(\lambda, P, T, Q) q
$$

Here $A$ and $B$ are known functions of $\lambda$, the atmospheric pressure $P$, and the ambient temperature $T$ and humidity $Q$. As before, $t$ is in ${ }^{\circ} \mathrm{C}$ and $q$ is in $\mathrm{kg} \mathrm{m}^{-3}$. Friehe et al. (1975) demonstrated how to derive eq 28 from an equation for the bulk refractive index of air. Table 3 lists the $A$ and $B$ functions that I thus derived from expressions for the refractive index for visible (Owens 1967) and for near-millimeter wavelengths (Bean and Dutton 1966, Gurvich 1968, Wesely 1976, McMillan et al. 1983). Although the table shows $A$ and $B$ for a wavelength of $0.55 \mu \mathrm{m}$, the functions vary so little with wavelength that they should represent $n$ throughout the visible region. Because the refractive index is a much more complex function in the infrared (Hill et al. 1980), I will not treat that region.

Table 3. Functions $A$ and $B$ for $0.55-\mu \mathrm{m}$ and millimeter wavelengths. $P$ is in $\mathrm{hPa}, T$ is in kelvins, and $Q$ is in $\mathbf{k g ~ m}^{-3}$.

\begin{tabular}{ccc} 
Wavelength & $10^{6} \mathrm{~A}$ & $10^{6} \mathrm{~B}$ \\
\hline $0.55 \mu \mathrm{m}$ & $-79.0\left(P / T^{2}\right)$ & -56.4 \\
millimeter & $-\left[77.6 P+1.73 \times 10^{6} \mathrm{Q}\right] / T^{2}$ & $1.73 \times 10^{6} / T^{2}$ \\
\hline
\end{tabular}


From eq 28 the refractive index spectrum $\Phi_{\mathrm{n}}(k)$ at wavenumber $k$ is

$$
\Phi_{\mathrm{n}}(k)=A^{2} \Phi_{\mathrm{t}}(k)+B^{2} \Phi_{\mathrm{q}}(k)+2 A B C o_{\mathrm{tq}}(k) .
$$

Therefore, by making simultaneous measurements of the temperature and humidity spectra and the $t-q$ cospectrum, I can compute the refractive index spectrum for an arbitrary electromagnetic wavelength. Since $\Phi_{\mathrm{t}}(k), \Phi_{\mathrm{q}}(k)$ and $\mathrm{Co}_{\mathrm{tq}}(k)$ are all proportional to $\epsilon^{-1 / 3} k^{-5 / 3}$ in an inertial-convective subrange, $\Phi_{\mathrm{n}}(k)$ should be also. Specifically,

$$
\Phi_{\mathrm{n}}(k)=\beta N_{\mathrm{n}} \epsilon^{-1 / 3} k^{-5 / 3}
$$

where $N_{\mathrm{n}}$ is the dissipation rate of half the refractive index variance, and $\beta$ is the same Kolmogorov constant I have used for the other scalar spectra (Hill 1978).

In studies of electromagnetic wave propagation in the atmosphere, another representation for spectra in the inertial-convective subrange arises. This involves the structure parameters $C_{\mathrm{t}}^{2}, C_{\mathrm{q}}^{2}, C_{\mathrm{tq}}$ and $C_{\mathrm{n}}^{2}$ :

$$
\begin{aligned}
& \Phi_{\mathrm{t}}(k)=0.249 C_{\mathrm{t}}^{2} k^{-5 / 3} \\
& \Phi_{\mathrm{q}}(k)=0.249 C_{\mathrm{q}}^{2} k^{-5 / 3} \\
& C o_{\mathrm{tq}}(k)=0.249 C_{\mathrm{tq}} k^{-5 / 3} \\
& \Phi_{\mathrm{n}}(k)=0.249 C_{\mathrm{n}}^{2} k^{-5 / 3}
\end{aligned}
$$

Clearly, from eq 29 the refractive index structure parameter is related to the structure parameters for $t, q$ and $t-q$ by

$$
C_{\mathrm{n}}^{2}=A^{2} C_{\mathrm{t}}^{2}+B^{2} C_{\mathrm{q}}^{2}+2 A B C_{\mathrm{tq}}
$$

Scintillometers, for example, measure $C_{n}^{2}$ directly. Thus, two ways exist to investigate the refractive index spectrum - with electro-optical instruments or with small, fast-responding meteorological instruments. Portman et al. (1962) and Ryznar (1963) did some of the early work on electro-optical propagation over snow and its relation to atmospheric turbulence.

Figures 15 and 16 show $0.55-\mu \mathrm{m}\left(\Phi_{s s}\right)$ and millimeter $\left(\Phi_{\mathrm{mm}}\right)$ refractive index spectra computed using eq 29 from the temperature and humidity spectra and the $t-q$ cospectra that $I$ have been discussing. The spectra are again made nondimensional with surface-layer scaling, and the dashed line is the modified Kansas temperature spectrum (eq 6). These, I believe, are the first refractive index spectra for either $0.55-\mu \mathrm{m}$ or millimeter wavelength light ever obtained over snow. And only a few visible (Friehe et al. 1975, Antonia et al. 1978) and millimeter (Priestley and Hill 1985) wavelength refractive index spectra have been published for other surfaces.

The two sets of refractive index spectra look like each other and also like the scalar spectra and cospectra I presented earlier. That is, both sets of spectra have more energy at low frequency than does the Kansas neutral-stability temperature spectrum-again because of topographic effects. Both sets, however, join the Kansas spectrum at higher frequency but evidently begin their inertial-convective subranges at lower frequency than in the Kansas spectrum. 


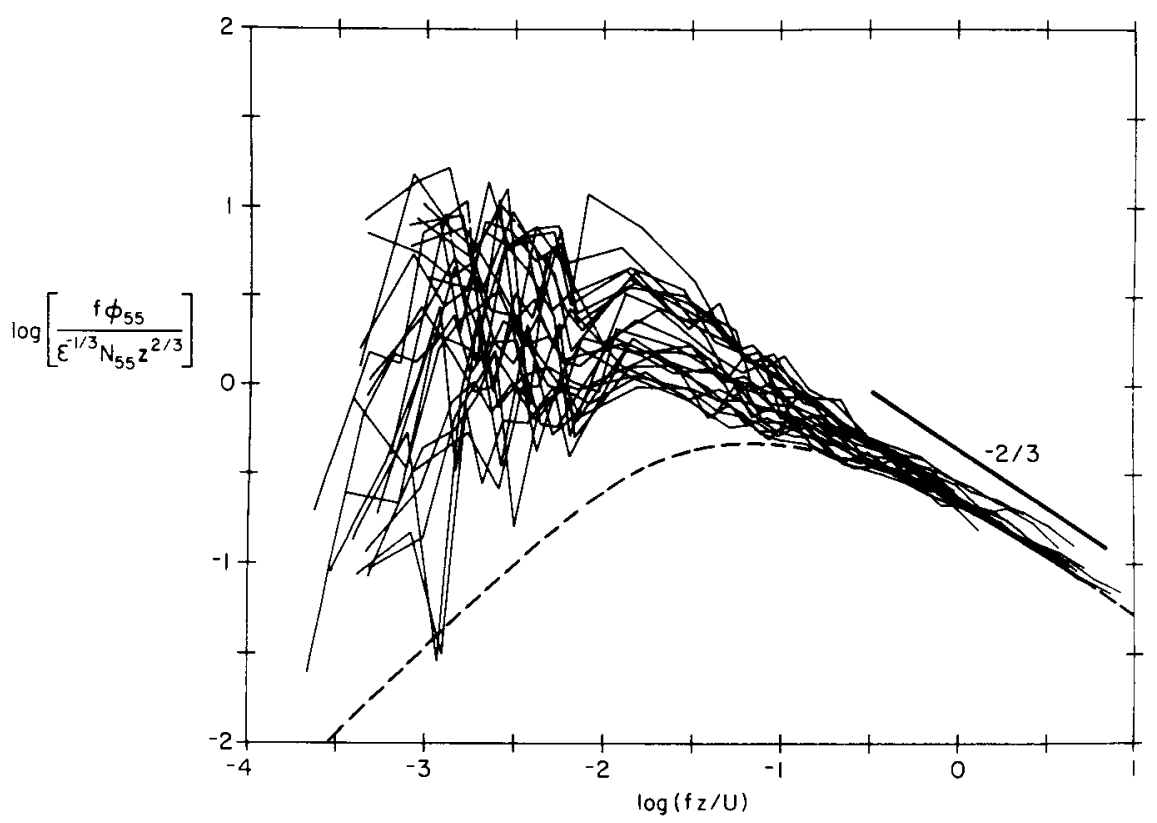

Figure 15. Twenty-four nondimensional refractive index spectra for light of $0.55-\mu m$ wavelength. The dashed line is the Kansas neutral-stability temperature spectrum (eq 6).

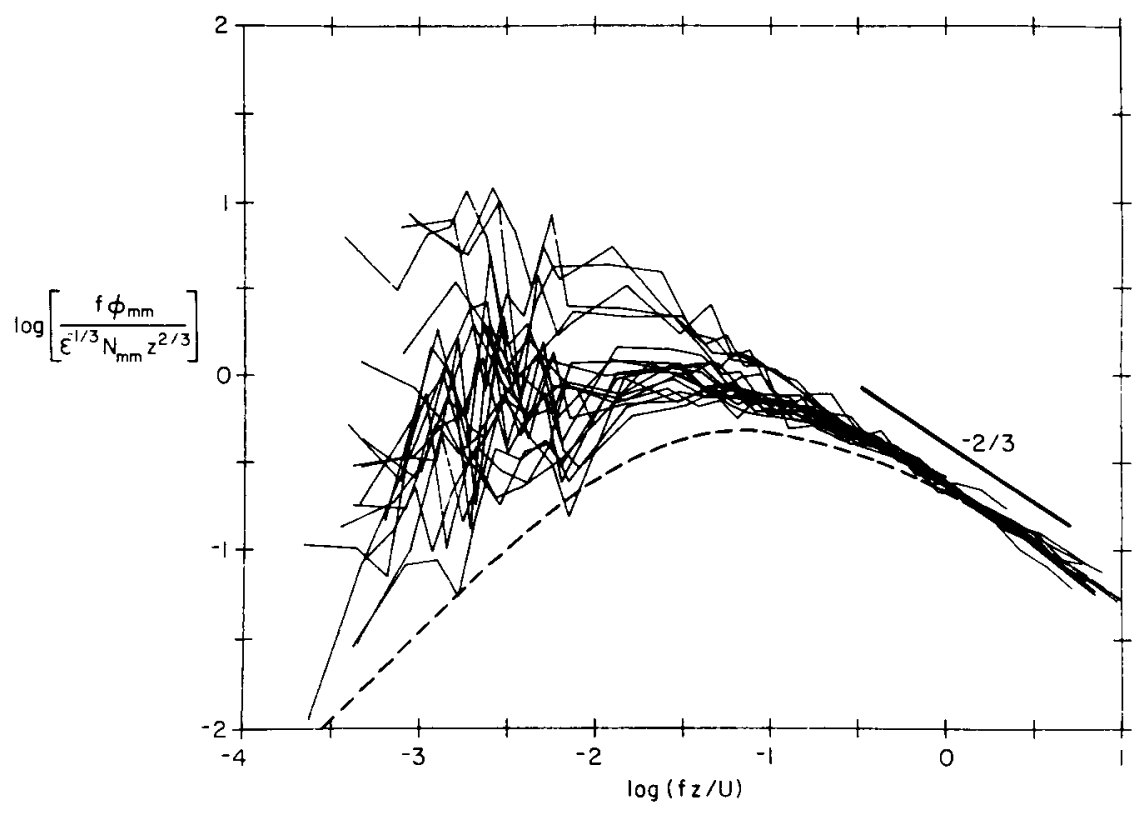

Figure 16. Twenty nondimensional refractive index spectra for light of nearmillimeter wavelength. 
Table 4. Values of the spectrally derived refractive index structure parameters for $0.55-\mu \mathrm{m}$ and millimeter wavelengths and the relative contributions of temperature and humidity fluctuations and the $t-q$ covariance to the millimeter structure parameter.

\begin{tabular}{rccccc}
\multicolumn{7}{c}{$10^{15} \mathrm{C}_{n}^{2}\left(\mathrm{~m}^{-2 / 3}\right)$} & \multicolumn{3}{l}{ Contributions to $m m \mathrm{C}_{n}^{2}$} \\
\cline { 5 - 7 } Run & $0.55 \mu m$ & $m m$ & $\mathrm{t}$ & $\mathrm{q}$ & $\mathrm{t}-\mathrm{q}$ \\
\hline & & & & & \\
1.1 & 3.57 & 9.57 & 0.38 & 0.29 & 0.33 \\
1.2 & 2.19 & 9.38 & 0.24 & 0.41 & 0.35 \\
2.1 & 2.44 & 10.1 & 0.24 & 0.39 & 0.36 \\
2.2 & 2.96 & 14.4 & 0.21 & 0.39 & 0.40 \\
3.1 & 0.18 & 0.78 & 0.23 & 0.73 & 0.04 \\
4.1 & 0.09 & 3.76 & 0.02 & 1.07 & -0.09 \\
4.2 & 0.14 & 5.37 & 0.03 & 0.86 & 0.11 \\
5.1 & 0.19 & 15.1 & 0.01 & 0.88 & 0.11 \\
5.2 & 0.14 & 15.2 & 0.01 & 0.90 & 0.09 \\
6.1 & 2.29 & & & & \\
6.2 & 3.14 & & & & \\
6.3 & 2.46 & & & & \\
7.1 & 1.97 & & & & \\
7.2 & 2.66 & & & & \\
9.1 & 0.26 & 9.07 & 0.03 & 0.73 & 0.24 \\
9.2 & 0.39 & 9.58 & 0.04 & 0.71 & 0.25 \\
10.1 & 0.47 & 11.7 & 0.04 & 0.70 & 0.26 \\
10.2 & 0.25 & 6.37 & 0.04 & 0.69 & 0.27 \\
10.3 & 1.44 & 12.2 & 0.12 & 0.70 & 0.17 \\
11.1 & 3.51 & 3.55 & 1.01 & 0.09 & -0.10 \\
11.2 & 6.36 & 2.24 & 2.88 & 0.80 & -2.67 \\
12.1 & 0.17 & 7.43 & 0.02 & 1.09 & -0.11 \\
13.1 & 2.06 & 2.20 & 0.94 & 0.13 & -0.07 \\
13.2 & 4.72 & 5.55 & 0.85 & 0.07 & 0.07 \\
14.1 & 2.61 & 2.37 & 1.10 & 0.45 & -0.55 \\
\hline & & & & &
\end{tabular}

With the presence of a conspicuous inertial-convective subrange in each refractive index spectrum, it is possible to find $C_{\mathrm{n}}^{2}$ for each. Table 4 lists these values. The table also lists the contributions to the millimeter $C_{\mathrm{n}}^{2}$ value from the temperature and humidity spectra and the $t-q$ cospectrum (see eq 35 ). Despite the low temperatures, humidity fluctuations generally make the largest contribution to the millimeter $C_{\mathrm{n}}^{2}$ value. The $t-q$ covariance is usually next in importance and can make a negative contribution, thereby offsetting relatively large $t$ or $q$ contributions. The temperature fluctuations, though generally making the smallest contribution, are seldom negligible. Consequently all three terms in eq 29 or 35 are necessary for accurately measuring $\Phi_{\mathrm{n}}$ or $C_{\mathrm{n}}^{2}$ in the millimeter region over snow.

The temperature spectrum always contributed at least $96 \%$ to the $0.55-\mu \mathrm{m} C_{\mathrm{n}}^{2}$ value, so I have not provided a similar breakdown for this wavelength in Table 4. McBean and Elliott (1981) also found that temperature fluctuations far outweighed other contributions to $C_{\mathrm{n}}^{2}$ in the visible region over land. Over the ocean, on the other hand, Antonia et al. (1978) reported that the $t-q$ contribution to $C_{\mathrm{n}}^{2}$ could be $5-10 \%$ even though the $q$ contribution was less than $1 \%$.

During the experiment, another group measured $C_{\mathrm{n}}^{2}$ for visible wavelengths with an optical scintillometer (Wang et al. 1978) placed near my instrument mast. The optical path was $300 \mathrm{~m}$ long and roughly $2 \mathrm{~m}$ above the surface. Figure 17 compares my spectrally derived $0.55-\mu \mathrm{m}$ 


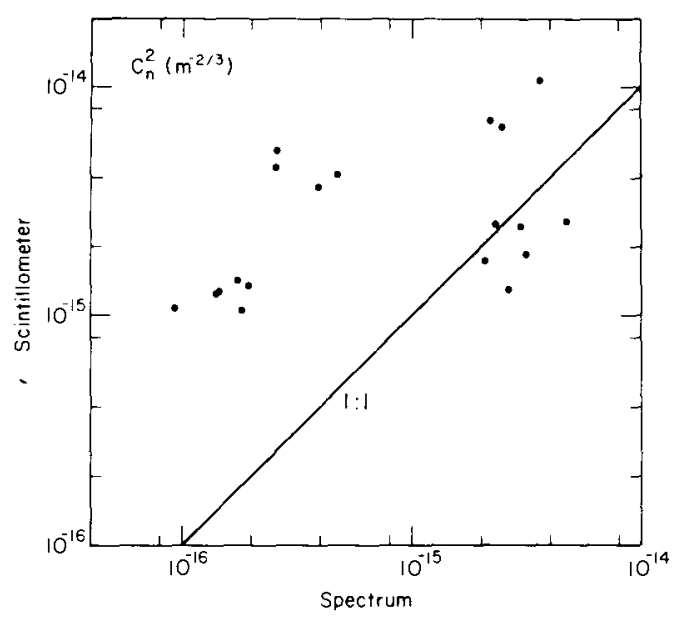

Figure 17. Comparison of simultaneous scintillometer and spectrally derived values of $\mathrm{C}_{n}^{2}$ for visible light.

$C_{\mathrm{n}}^{2}$ values with these simultaneous scintillometer measurements. The two methods agree reasonably well at high spectral $C_{\mathrm{n}}^{2}$ but not as well at low spectral $C_{\mathrm{n}}^{2}$. Seeing this and then looking more closely at how the scintillometer was set up, I found that it was operating too near its noise level (Ochs et al. 1977) and, thus, was incapable of resolving the low $C_{\mathrm{n}}^{2}$ values encountered. Hence, this first experimental attempt to verify eq 35 over snow was not entirely successful. Kohsiek (1985), however, did find good agreement between infrared $C_{n}^{2}$ values obtained with a $\mathrm{CO}_{2}$ laser and with fast-responding meteorological instruments over varied terrain in the Netherlands. And Priestley and Hill (1985) found reasonable agreement between radio-wavelength $C_{\mathrm{n}}^{2}$ values obtained at $\mathrm{BAO}$ with a radio refractometer and with meteorological instruments. Evidence is, therefore, mounting that the theoretical arguments that lead to eq 29 and 35 are basically sound.

\section{CONCLUSIONS}

I have described an extensive set of turbulence spectra and cospectra collected in nearneutral conditions over snow. All of the spectra- $u, w, t$ and $q-$ and cospectra- $u-w, w-t$, $w-q$ and $t-q$-have high energy at low frequency because of flow disturbances associated with the forested hills bordering the site. With the exception of $\mathrm{Co}_{\mathrm{uw}}$, all, nevertheless, have the expected inertial or inertial-convective subrange behavior. The erratic behavior of $\mathrm{Co}_{\mathrm{uw}}$ is, thus, primary evidence of flow disturbance.

The phase and coherence spectra, especially $C h_{\mathrm{tq}}$, suggest a difference in transfer processes at large and small scales at this topographically complex site. With the atmospheric boundary layer generally having slightly stable stratification, I found evidence of internal gravity waves when the surface layer was also stably stratified. These low-frequency waves and the low-frequency turbulence induced by the topography generally combined to produce confused cospectra with vacillating sign at low frequency. At higher frequency the spectra and cospectra were better behaved, thus indicating that here the fluctuations resulted strictly from turbulent processes that were nearly in equilibrium with the smooth, flat snow surface surrounding my instrument mast. 
With simultaneous measurements of temperature and humidity spectra and temperaturehumidity cospectra, I could compute refractive index spectra for light of visible and millimeter wavelengths. These refractive index spectra looked like the scalar spectra that yielded them; they had significant energy at low frequency and an inertial-convective subrange at high frequency. Over snow at the air temperatures encountered, the spectrum for visible light is determined almost entirely by temperature fluctuations. For the millimeter spectrum, on the other hand, humidity fluctuations are generally most important, but temperature fluctuations and the $t-q$ covariance cannot be ignored. These spectra yielded refractive index structure parameters $C_{\mathrm{n}}^{2}$ that ranged from $9 \times 10^{-17}$ to $6 \times 10^{-15} \mathrm{~m}^{-2 / 3}$ for visible light and from $8 \times$ $10^{-16}$ to $1.5 \times 10^{-14} \mathrm{~m}^{-2 / 3}$ for millimeter wavelengths.

\section{LITERATURE CITED}

Andreas, E.L (1979) Analysis of crossed hot-film velocity data. DISA Information, 24: 15-23. Allendale, New Jersey: Dantec Electronics Inc.

Andreas, E.L (1986) A new method of measuring the snow-surface temperature. Cold Regions Science and Technology, 12: 139-156.

Andreas, E.L and A.P. Makshtas (1985) Energy exchange over Antarctic sea ice in the spring. Journal of Geophysical Research, 90: 7199-7212.

Andreas, E.L and B. Murphy (1986a) Bulk transfer coefficients for heat and momentum over leads and polynyas. Journal of Physical Oceanography, 16: 1875-1883.

Andreas, E.L and B. Murphy (1986b) Calibrating cylindrical hot-film anemometer sensors. Journal of Atmospheric and Oceanic Technology, 3: 283-298.

Andreas, E.L and C.A. Paulson (1979) Velocity spectra and cospectra and integral statistics over Arctic leads. Quarterly Journal of the Royal Meteorological Society, 105: 1053-1070.

Antonia, R.A. and A.J. Chambers (1980) Wind-wave-induced disturbances in the marine surface layer. Journal of Physical Oceanography, 10: 611-622.

Antonia, R.A., A.J. Chambers and C.A. Friehe (1978) Statistical properties of optical refractive index fluctuations in the marine boundary layer. Boundary-Layer Meteorology, 15: 243-253.

Antonia, R.A., A.J. Chambers and B.R. Satyaprakash (1981) Kolmogorov constants for structure functions in turbulent shear flows. Quarterly Journal of the Royal Meteorological Society, 107: 579-589.

Banke, E.G. and S.D. Smith (1971) Wind stress over ice and over water in the Beaufort Sea. Journal of Geophysical Research, 76: 7368-7374.

Banke, E.G. and S.D. Smith (1973) Wind stress on Arctic sea ice. Journal of Geophysical Research, 78: 7871-7883.

Banke, E.G., S.D. Smith and R.J. Anderson (1980) Drag coefficients at AIDJEX from sonic anemometer measurements. In Sea Ice Processes and Models (R.S. Pritchard, Ed.). Seattle: University of Washington Press, p. 430-442.

Bean, B.R. and E.J. Dutton (1966) Radio Meteorology. U.S. Department of Commerce, National Bureau of Standards Monograph 92.

Bradley, E.F. (1980) An experimental study of the profiles of wind speed, shearing stress and turbulence at the crest of a large hill. Quarterly Journal of the Royal Meteorological Society, 106: 101-123.

Bradley, E.F., R.A. Antonia and A.J. Chambers (1981) Temperature structure in the atmospheric surface layer: I. The budget of temperature variance. Boundary-Layer Meteorology, 20: 275-292. 
Brown, R.A. (1980) Longitudinal instabilities and secondary flows in the planetary boundary layer: A review. Reviews of Geophysics and Space Physics, 18: 683-697.

Buck, A.L. (1976) The variable-path Lyman-alpha hygrometer and its operating characteristics. Bulletin of the American Meteorological Society, 57: 1113-1118.

Buck, A.L. (1977) Lyman-alpha radiation source with high spectra purity. Applied Optics, 16: 2634-2636.

Buck, A.L. and L.G. Post (1980) RSF/RAF Lyman-alpha hygrometer model LA-3. Operating and Maintenance Manual 083-032-007. Research Systems Facility, National Center for Atmospheric Research, Boulder, Colorado.

Busch, N.E. (1973) On the mechanics of atmospheric turbulence. In Workshop on Micrometeorology (D.A. Haugen, Ed.). Boston: American Meteorological Society, p. 1-65.

Caughey, S.J. (1977) Boundary-layer turbulence spectra in stable conditions. BoundaryLayer Meteorology, 11: 3-14.

Champagne, F.H., C.A. Friehe, J.C. LaRue and J.C. Wyngaard (1977) Flux measurements, flux estimation techniques, and fine-scale turbulence measurements in the unstable surface layer over land. Journal of the Atmospheric Sciences, 34: 515-530.

Corrisin, S. (1951) On the spectrum of isotropic temperature fluctuations in an isotropic turbulence. Journal of Applied Physics, 22: 469-473.

Dyer, A.J. (1974) A review of flux-profile relationships. Boundary-Layer Meteorology, 7: 363-372.

Dyer, A.J. and E.F. Bradley (1982) An alternative analysis of flux-gradient relationships at the 1976 ITCE. Boundary-Layer Meteorology, 22: 3-19.

Fairall, C.W., K.L. Davidson and G.E. Schacher (1979) Humidity effects and sea salt contamination of atmospheric temperature sensors. Journal of Applied Meteorology, 18: 12371239.

Fairall, C.W. and S.E. Larsen (1986) Inertial-dissipation methods and turbulent fluxes at the air-ocean interface. Boundary-Layer Meteorology, 34: 287-301.

Fairall, C.W., G.E. Schacher and K.L. Davidson (1980) Measurements of the humidity structure function parameters, $C_{\mathrm{q}}^{2}$ and $C_{\mathrm{Tq}}$, over the ocean. Boundary-Layer Meteorology, 19: 81-92.

Friehe, C.A., J.C. LaRue, F.H. Champagne, C.H. Gibson and G.F. Dreyer (1975) Effects of temperature and humidity fluctuations on the optical refractive index in the marine boundary layer. Journal of the Optical Society of America, 65: 1502-1511.

Garratt, J.R. (1977) Review of drag coefficients over oceans and continents. Monthly Weather Review, 105: 915-929.

Gurvich, A.S. (1968) Effect of absorption on the fluctuation in signal level during atmospheric propagation. Radio Engineering and Electronic Physics, 13: 1687-1694.

Haugen, D.A., J.C. Kaimal and E.F. Bradley (1971) An experimental study of Reynolds stress and heat flux in the atmospheric surface layer. Quarterly Journal of the Royal Meteorological Society, 97: 168-180.

Hicks, B.B. and H.C. Martin (1972) Atmospheric turbulent fluxes over snow. BoundaryLayer Meteorology, 2: 496-502.

Hill, R.J. (1978) Spectra of fluctuations in refractivity, temperature, humidity, and the temperature-humidity cospectrum in the inertial and dissipation ranges. Radio Science, 13: 953961.

Hill, R.J., S.F. Clifford and R.S. Lawrence (1980) Refractive-index and absorption fluctuations in the infrared caused by temperature, humidity, and pressure fluctuations. Journal of the Optical Society of America, 70: 1192-1205.

Hunt, J.C.R., J.C. Kaimal and J.E. Gaynor (1985) Some observations of turbulence structure in stable layers. Quarterly Journal of the Royal Meteorological Society, 111: 793-815. 
Jackson, P.S. and J.C.R. Hunt (1975) Turbulent wind flow over a low hill. Quarterly Journal of the Royal Meteorological Society, 101: 929-955.

Kaimal, J.C. (1975) Sensors and techniques for direct measurement of turbulent fluxes and profiles in the atmospheric surface layer. Atmospheric Technology, 7: 7-14.

Kaimal, J.C., R.A. Eversole, D.H. Lenschow, B.B. Stankov, P.H. Kahn and J.A. Businger (1982) Spectral characteristics of the convective boundary layer over uneven terrain. Journal of the Atmospheric Sciences, 39: 1098-1114.

Kaimal, J.C. and D.A. Haugen (1971) Comments on "Minimizing the leveling error in Reynolds stress measurements by filtering." Journal of Applied Meteorology, 10: 337-339.

Kaimal, J.C., J.C. Wyngaard, D.A. Haugen, O.R. Coté, Y. Izumi, S.J. Caughey and C.J. Readings (1976) Turbulence structure in the convective boundary layer. Journal of the Atmospheric Sciences, 33: 2152-2169.

Kaimal, J.C., J.C. Wyngaard, Y. Izumi and O.R. Coté (1972) Spectral characteristics of surface-layer turbulence. Quarterly Journal of the Royal Meteorological Society, 98: 563589.

Kohsiek, W. (1982) Optical and in situ measuring of structure parameters relevant to temperature and humidity, and their application to the measuring of sensible and latent heat flux. NOAA Technical Memorandum ERL WPL-96. Wave Propagation Laboratory, Boulder, Colorado. NTIS: PB82-230533.

Kohsiek, W. (1984) Inertial subrange correlation between temperature and humidity fluctuations in the unstable surface layer above vegetated terrains. Boundary-Layer Meteorology, 29: 211-224.

Kohsiek, W. (1985) A comparison between line-averaged observation of $C_{\mathrm{n}}^{2}$ from scintillation of a $\mathrm{CO}_{2}$ laser beam and time-averaged in situ observations. Journal of Climate and Applied Meteorology, 24: 1099-1103.

Large, W.G. and S. Pond (1981) Open ocean momentum flux measurements in moderate to strong winds. Journal of Physical Oceanography, 11: 324-336.

Large, W.G. and S. Pond (1982) Sensible and latent heat flux measurements over the ocean. Journal of Physical Oceanography, 12: 464-482.

LaRue, J.C., T. Deaton and C.H. Gibson (1975) Measurement of high-frequency turbulent temperature. Review of Scientific Instruments, 46: 757-764.

Leavitt, E. (1975) Spectral characteristics of surface layer turbulence over the tropical ocean. Journal of Physical Oceanography, 5: 157-163.

Mason, P.J. and J.C. King (1984) Atmospheric flow over a succession of nearly two-dimensional ridges and valleys. Quarterly Journal of the Royal Meteorological Society, 110: 821845 .

Mason, P.J. and J.C. King (1985) Measurements and predictions of flow and turbulence over an isolated hill of moderate slope. Quarterly Journal of the Royal Meteorological Society, 111: 617-640.

McBean, G.A. (1971) The variations of the statistics of wind, temperature and humidity fluctuations with stability. Boundary-Layer Meteorology, 1: 438-457.

McBean, G.A. and J.A. Elliott (1981) Pressure and humidity effects on optical refractiveindex fluctuations. Boundary-Layer Meteorology, 20: 101-109.

McBean, G.A. and M. Miyake (1972) Turbulent transfer mechanisms in the atmospheric surface layer. Quarterly Journal of the Royal Meteorological Society, 98: 383-398.

McKay, D.C. and G.W. Thurtell (1978) Measurements of the energy fluxes involved in the energy budget of a snow cover. Journal of Applied Meteorology, 17: 339-349.

McMillan, R.W., R.A. Bohlander, G.R. Ochs, R.J. Hill and S.F. Clifford (1983) Millimeter wave atmospheric turbulence measurements: Preliminary results and instrumentation for future measurements. Optical Engineering, 22: 32-39. 
Miyake, M. and G. McBean (1970) On the measurement of vertical humidity transport over land. Boundary-Layer Meteorology, 1: 88-101.

Nicholls, S. and C.J. Readings (1981) Spectral characteristics of surface layer turbulence over the sea. Quarterly Journal of the Royal Meteorological Society, 107: 591-614.

Ochs, G.R., R.F. Quintana and G.F. Miller (1977) An optical device for measuring refractive index fluctuation in the atmosphere. NOAA Technical Memorandum WPL-30. Wave Propagation Laboratory, Boulder, Colorado. NTIS: ADA051 435/6GI.

Ohtaki, E. (1985) On the similarity in atmospheric fluctuations of carbon dioxide, water vapor and temperature over vegetated fields. Boundary-Layer Meteorology, 32: 25-37.

Owens, J.C. (1967) Optical refractive index of air: Dependence on pressure, temperature and composition. Applied Optics, 6: 51-59.

Panofsky, H.A. and J.A. Dutton (1984) Atmospheric Turbulence: Models and Methods for Engineering Applications. New York: John Wiley and Sons.

Panofsky, H.A., D. Larko, R. Lipschutz, G. Stone, E.F. Bradley, A.J. Bowen and J. Hojstrup (1982) Spectra of velocity components over complex terrain. Quarterly Journal of the Royal Meteorological Society, 108: 215-230.

Paquin, J.E. and S. Pond (1971) The determination of the Kolmogoroff constants for velocity, temperature and humidity fluctuations from second- and third-order structure functions. Journal of Fluid Mechanics, 50: 257-269.

Phelps, G.T. and S. Pond (1971) Spectra of the temperature and humidity fluctuations and of the fluxes of moisture and sensible heat in the marine boundary layer. Journal of the Atmospheric Sciences, 28: 918-928.

Pond, S., G.T. Phelps, J.E. Paquin, G. McBean and R.W. Stewart (1971) Measurements of the turbulent fluxes of momentum, moisture and sensible heat over the ocean. Journal of the Atmospheric Sciences, 28: 901-917.

Portman, D.J., F.C. Elder, E. Ryznar and V.E. Noble (1962) Some optical properties of turbulence in stratified flow near the ground. Journal of Geophysical Research, 67: 3223-3235. Priestley, J.T. and R.J. Hill (1985) Measuring high-frequency humidity, temperature and radio refractive index in the surface layer. Journal of Atmospheric and Oceanic Technology, 2: 233-251.

Raupach, M.R. (1978) Infrared fluctuation hygrometry in the atmospheric surface layer. Quarterly Journal of the Royal Meteorological Society, 104: 309-322.

Ryznar, E. (1963) Visual resolution and optical scintillation over snow. Journal of Applied Meteorology, 2: 526-530.

Schmitt, K.F., C.A. Friehe and C.H. Gibson (1978) Humidity sensitivity of atmospheric temperature sensors by salt contamination. Journal of Physical Oceanography, 8: 151-161. Schmitt, K.F., C.A. Friehe and C.H. Gibson (1979) Structure of marine surface layer turbulence. Journal of the Atmospheric Sciences, 36: 602-618.

Smedman, A.-S. and H. Bergström (1984) Flow characteristics above a very low and gently sloping hill. Boundary-Layer Meteorology, 29: 21-37.

Smith, S.D. (1972) Wind stress and turbulence over a flat ice floe. Journal of Geophysical Research, 77: 3886-3901.

Smith, S.D. and R.J. Anderson (1984) Spectra of humidity, temperature, and wind over the sea at Sable Island, Nova Scotia. Journal of Geophysical Research, 89: 2029-2040.

Smith, S.D., R.J. Anderson, G. den Hartog, D.R. Topham and R.G. Perkin (1983) An investigation of a polynya in the Canadian Archipelago, 2, Structure of turbulence and sensible heat flux. Journal of Geophysical Research, 88: 2900-2910.

Smith, S.D., E.G. Banke and O.M. Johannessen (1970) Wind stress and turbulence over ice in the Gulf of St. Lawrence. Journal of Geophysical Research, 75: 2803-2812. 
Tennekes, H. and J.L. Lumley (1972) $A$ First Course in Turbulence. Cambridge, Massachusetts: MIT Press.

Teunissen, H.W. (1980) Structure of mean winds and turbulence in the planetary boundary layer over rural terrain. Boundary-Layer Meteorology, 19: 187-221.

Thorpe, M.R., E.G. Banke and S.D. Smith (1973) Eddy correlation measurements of evaporation and sensible heat flux over Arctic sea ice. Journal of Geophysical Research, 78: 3573-3584.

Tsvang, L.R., S.L. Zubkovskii, B.A. Kader, M.A. Kallistratova, T. Foken, V. Gerstmann, A. Przadka, Ya. Pretel, Ya. Zeleny and J. Keder (1985) International Turbulence Comparison Experiment (ITCE-81). Boundary-Layer Meteorology, 31: 325-347.

Wang, T.-i., G.R. Ochs and S.F. Clifford (1978) A saturation-resistant optical scintillometer to measure $C_{\mathrm{n}}^{2}$. Journal of the Optical Society of America, 68: 334-338.

Wesely, M.L. (1976) The combined effect of temperature and humidity fluctuations on refractive index. Journal of Applied Meteorology, 15: 43-49.

Williams, R.M. and C.A. Paulson (1977) Microscale temperature and velocity spectra in the atmospheric boundary layer. Journal of Fluid Mechanics, 83: 547-567.

Wyngaard, J.C. (1973) On surface-layer turbulence. In Workshop on Micrometeorology (D.A. Haugen, Ed.). Boston: American Meteorological Society, p. 101-149.

Wyngaard, J.C. and O.R. Coté (1971) The budgets of turbulent kinetic energy and temperature variance in the atmospheric surface layer. Journal of the Atmospheric Sciences, 28: 190201.

Wyngaard, J.C. and O.R. Cote (1972) Cospectral similarity in the atmospheric surface layer. Quarterly Journal of the Royal Meteorological Society, 98: 590-603.

Wyngaard, J.C., W.T. Pennell, D.H. Lenschow and M.A. LeMone (1978) The temperaturehumidity covariance budget in the convective boundary layer. Journal of the Atmospheric Sciences, 35: 47-58.

Yaglom, A.M. (1977) Comments on wind and temperature flux-profile relationships. Boundary-Layer Meteorology, 11: 89-102.

Yamamoto, G. (1975) Generalization of the KEYPS formula in diabatic conditions and related discussion on the critical Richardson number. Journal of the Meteorological Society of Japan, 53: 189-195.

Yelagina, L.G., B.M. Koprov and D.F. Timanovskiy (1978) Certain characteristics of the atmospheric surface layer above snow. Izvestiya, Atmospheric and Oceanic Physics, 14: 652655 . 